\author{
SANDIA REPORT \\ SAND2010-8398 \\ Unlimited Release \\ Printed November 2010
}

\title{
International Perspectives on Mitigating Laboratory Biorisks
}

Carlos A. Salazar and William J. Pinard

Prepared by

Sandia National Laboratories

Albuquerque, New Mexico 87185 and Livermore, California 94550

Sandia National Laboratories is a multi-program laboratory managed and operated by Sandia Corporation, a wholly owned subsidiary of Lockheed Martin Corporation, for the U.S. Department of Energy's National Nuclear Security Administration under contract DE-AC04-94AL85000.

Approved for public release; further dissemination unlimited. 


\section{Issued by Sandia National Laboratories, operated for the United States Department of Energy by Sandia Corporation.}

NOTICE: This report was prepared as an account of work sponsored by an agency of the United States Government. Neither the United States Government, nor any agency thereof, nor any of their employees, nor any of their contractors, subcontractors, or their employees, make any warranty, express or implied, or assume any legal liability or responsibility for the accuracy, completeness, or usefulness of any information, apparatus, product, or process disclosed, or represent that its use would not infringe privately owned rights. Reference herein to any specific commercial product, process, or service by trade name, trademark, manufacturer, or otherwise, does not necessarily constitute or imply its endorsement, recommendation, or favoring by the United States Government, any agency thereof, or any of their contractors or subcontractors. The views and opinions expressed herein do not necessarily state or reflect those of the United States Government, any agency thereof, or any of their contractors.

Printed in the United States of America. This report has been reproduced directly from the best available copy.

Available to DOE and DOE contractors from

U.S. Department of Energy

Office of Scientific and Technical Information

P.O. Box 62

Oak Ridge, TN 37831

Telephone: $\quad$ (865) 576-8401

Facsimile: (865) 576-5728

E-Mail: reports@adonis.osti.gov

Online ordering: http://www.osti.gov/bridge

Available to the public from

U.S. Department of Commerce

National Technical Information Service

5285 Port Royal Rd.

Springfield, VA 22161

Telephone: $\quad$ (800) 553-6847

Facsimile: $\quad$ (703) 605-6900

E-Mail: $\quad$ orders@ntis.fedworld.gov

Online order: $\quad$ http://www.ntis.gov/help/ordermethods.asp?loc=7-4-0\#online

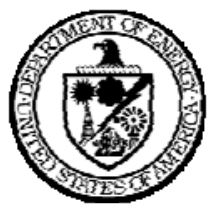


SAND2010-8398

Unlimited Release

Printed November 2010

\title{
International Perspectives on Mitigating Laboratory Biorisks
}

\author{
Carlos A. Salazar and William J. Pinard \\ International Biological Threat Reduction Program \\ Sandia National Laboratories \\ P.O. Box 5800 \\ Albuquerque, NM, USA 87185-1363
}




\section{Table of Contents}

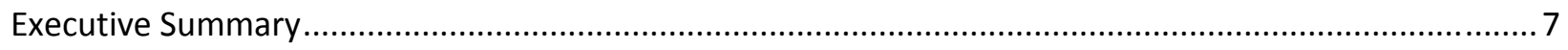

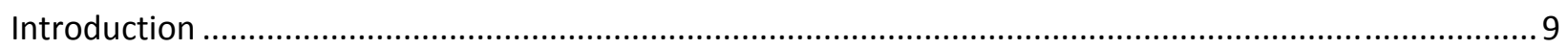

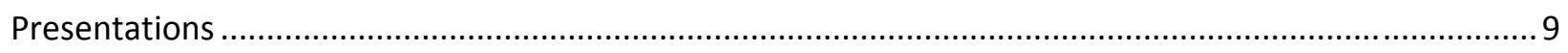

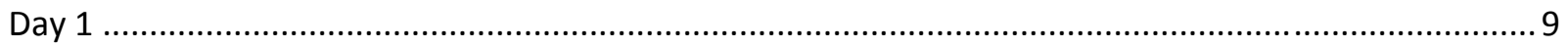

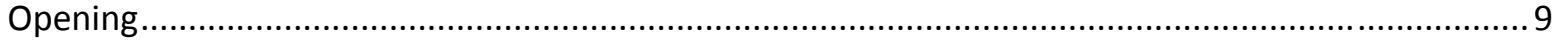

Session 1 - Challenges in Laboratory Biorisk Management ......................................................... 10

Breakout Session 1 - Challenges in Laboratory Biorisk Management ............................................. 14

Session 2 - Risk Assessment and Mitigation Measures …............................................................. 17

Breakout Session 2 - Risk Assessment and Mitigation Measures................................................... 18

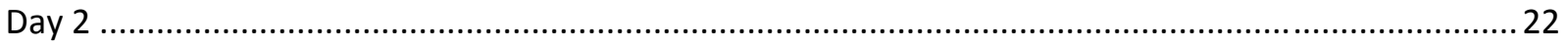

Session 3 - Biorisk Management System Performance …................................................................ 22

Breakout Session 3 - Biorisk Management System Performance ..................................................... 24

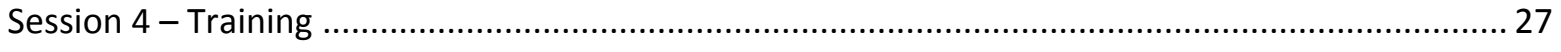

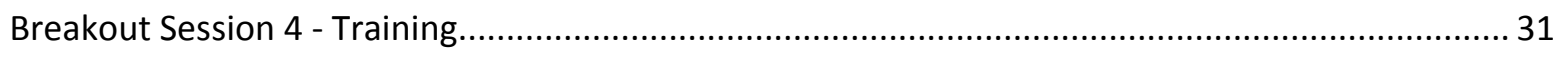

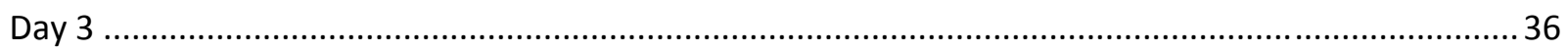

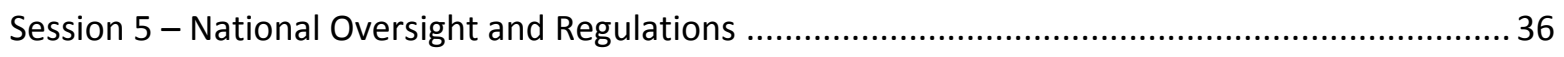

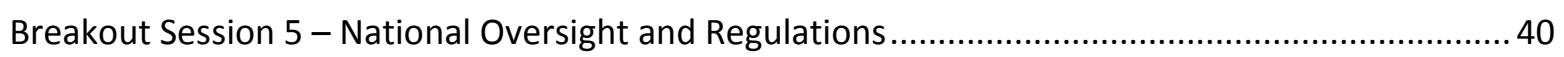

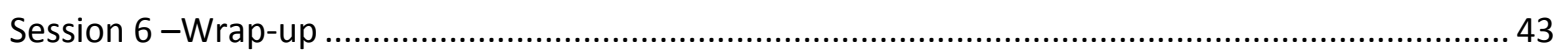

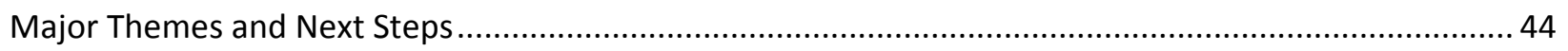

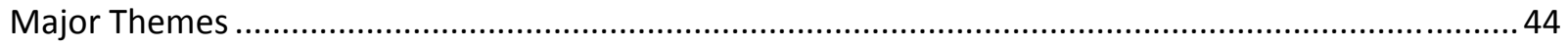

Next Steps

Recommendations to the Biological Weapons Convention .......................................................... 47

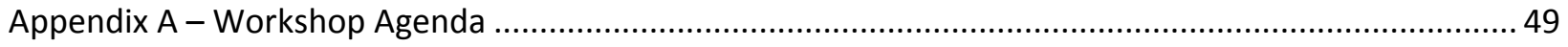

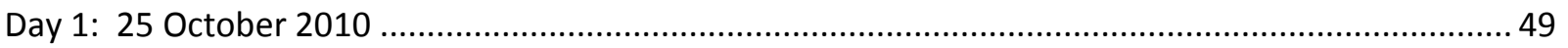

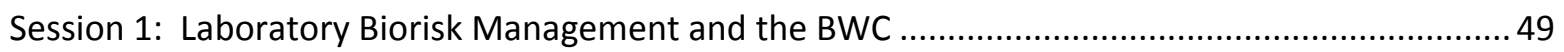

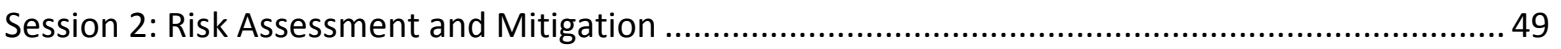

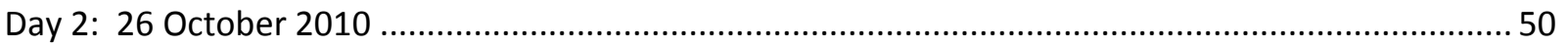

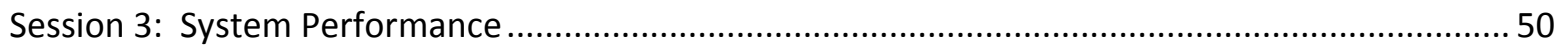

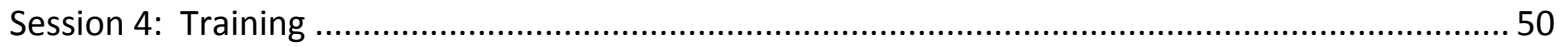

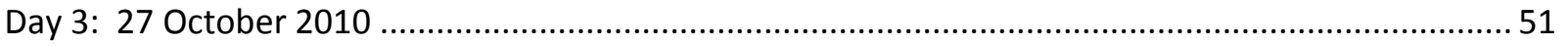

Session 5: National Biorisk Oversight and Regulations............................................................. 51

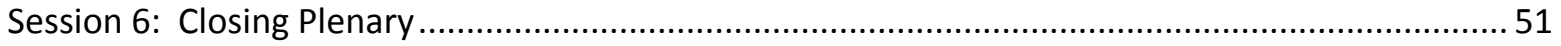




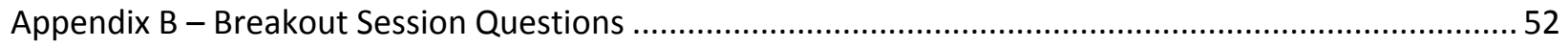

Session 1: Laboratory Biorisk Management and the BWC …........................................................ 52

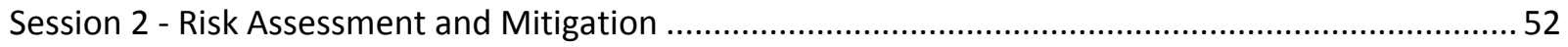

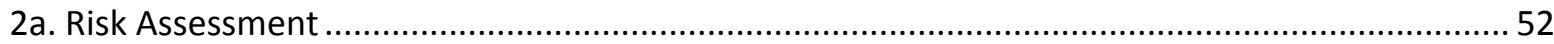

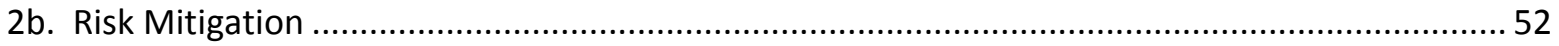

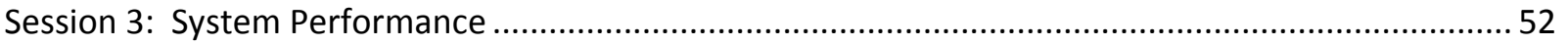

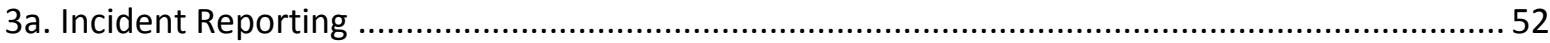

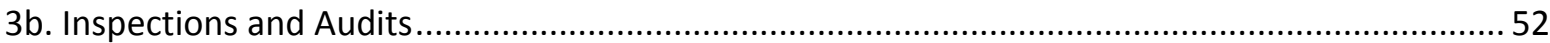

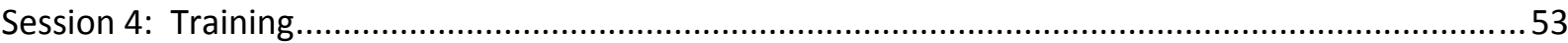

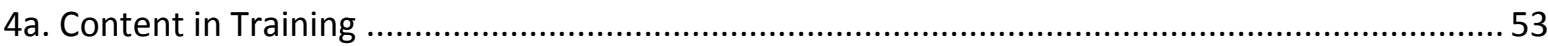

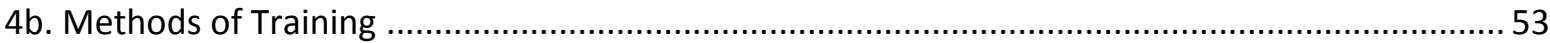

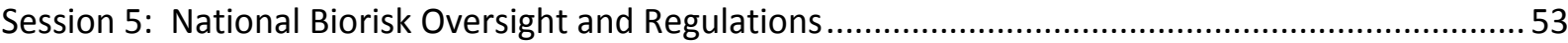

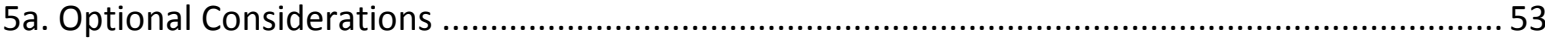

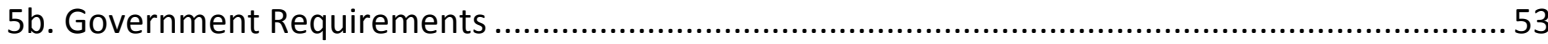

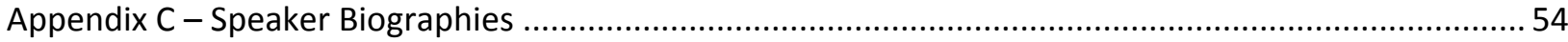

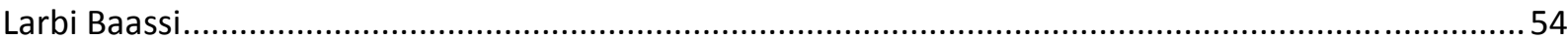

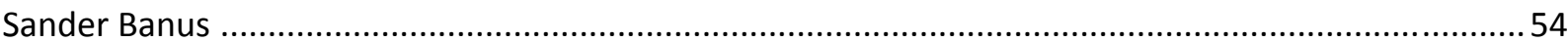

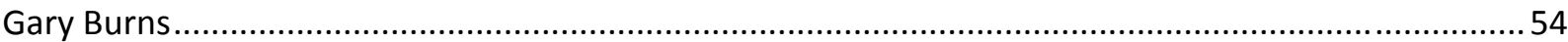

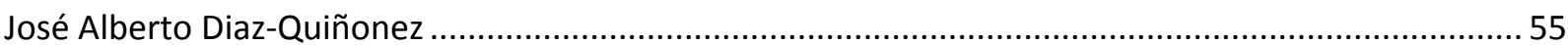

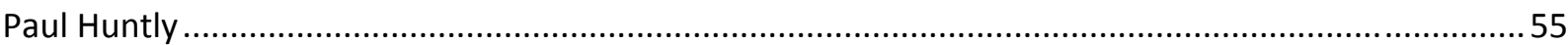

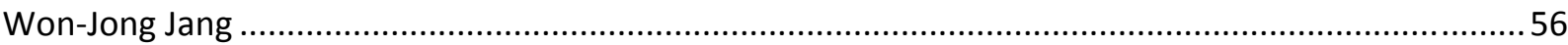

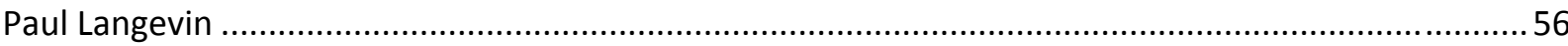

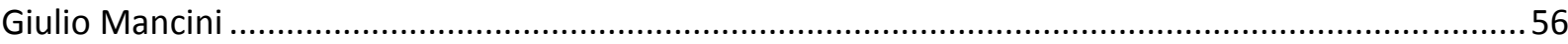

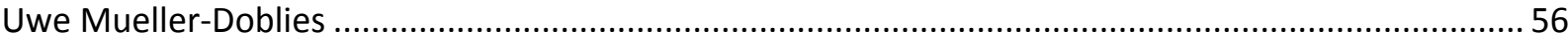

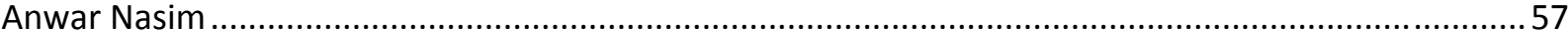

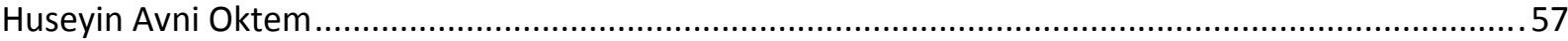

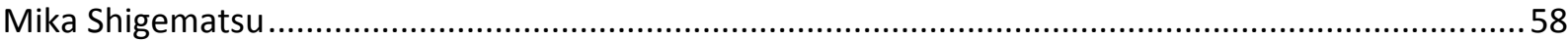

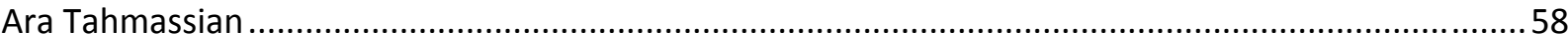

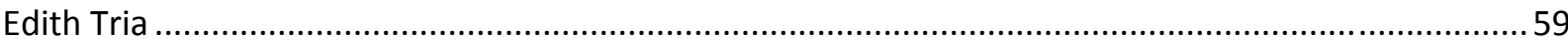

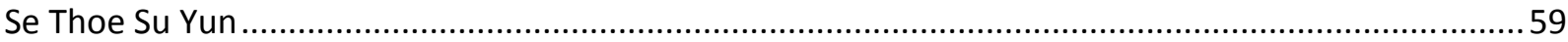

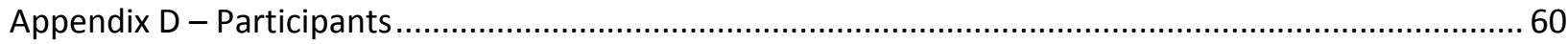

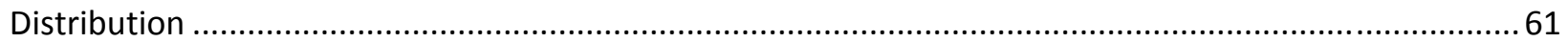




\section{Executive Summary}

The International Perspectives on Mitigating Laboratory Biorisks workshop, held at the Renaissance Polat Istanbul Hotel in Istanbul, Republic of Turkey, from October 25 to 27, 2010, sought to promote discussion between experts and stakeholders from around the world on issues related to the management of biological risk in laboratories. The event was organized by Sandia National Laboratories' International Biological Threat Reduction program, on behalf of the US Department of State Biosecurity Engagement Program and the US Department of Defense Cooperative Biological Engagement Program. The workshop came about as a response to US Under Secretary of State Ellen O. Tauscher's statements in Geneva on December 9, 2009, during the Annual Meeting of the States Parties to the Biological Weapons Convention. Pursuant to those remarks, the workshop was intended to provide a forum for interested countries to share information on biorisk management training, standards, and needs. Over the course of the meeting's three days, participants discussed diverse topics such as the role of risk assessment in laboratory biorisk management, strategies for mitigating risk, measurement of performance and upkeep, international standards, training and building workforce competence, and the important role of government and regulation. Participants expressed the multitude of challenges laboratories, institutions, countries, and the international system faced. Major themes of the conference included the importance of developing networks and partnerships, human capacity and the development of institutional and regulatory expertise, sustainability of risk management systems and efforts, the quality and character of risk management oversight, and the challenges of implementation for risk management systems.

As biological sciences continue to advance and new technologies and industries emerge, safety and security issues will impel governments and international bodies to find ways to regulate laboratories and institutions in order to safeguard their citizenry and their economies from biological risks. But high upfront costs, uncertainty, and misaligned perceptions may lead to improper regulation, unmitigated risks, and high societal costs. International forums like the Annual Meetings of States Parties to the Biological Weapons Convention can do much to support valuable risk reduction initiatives, galvanize national action, promote peaceful scientific cooperation, and build the foundations for safe and secure science. A series of recommendations for the Meeting of the States Parties emerged from this workshop.

- A statement from the 2010 Annual Meeting of States Parties in support of biorisk management could do much to increase the concept's exposure and legitimacy and provide momentum for future development and improvement.

- International discussions allow existing forums like the Annual Meeting of the States Parties to take up recent developments and galvanize national action in support for biorisk management.

- International forums like the Annual Meeting of the States Parties should underline the importance of harmonizing efforts between countries so the mitigation of risks posed by dangerous pathogens and toxins does not entail an end to scientific cooperation for peaceful purposes. 
- Utilizing risk management as a vehicle for increasing cooperation is a lofty goal that should be adopted by national governments and coordinated in international forums like the Meetings of the States Parties to the Biological Weapons Convention.

- It will be important to address concerns from the scientific and biorisk community and urge national governments to support effective training programs for mitigating biological risk. 


\section{Introduction}

The International Perspectives on Mitigating Laboratory Biorisks workshop, held at the Renaissance Polat Istanbul Hotel in Istanbul, Republic of Turkey, from October 25 to 27, 2010, sought to promote discussion between experts and stakeholders from around the world on issues related to the management of biological risk in laboratories. The event was organized by Sandia National Laboratories' International Biological Threat Reduction program, on behalf of the US Department of State Biosecurity Engagement Program and the US Department of Defense Cooperative Biological Engagement Program. The workshop came about as a response to US Under Secretary of State Ellen O. Tauscher's statements in Geneva on December 9, 2009, during the Annual Meeting of the States Parties to the Biological Weapons Convention (BWC). Pursuant to those remarks, the workshop was intended to provide a forum for interested countries to share information on biorisk management training, standards, and needs. Over the course of the meeting's three days, participants discussed diverse topics such as the role of risk assessment in laboratory biorisk management, strategies for mitigating risk, measurement of performance and upkeep, international standards, training and building workforce competence, and the important role of government and regulation. The meeting concluded with affirmations of the utility of international cooperation in this sphere and recognition of positive prospects for the future.

The workshop was organized as a series of short presentations by international experts on the field of biorisk management, followed by breakout sessions in which participants were divided into four groups and urged to discuss a particular topic with the aid of a facilitator and a set of guiding questions.

Rapporteurs were present during the plenary session as well as breakout sessions and in particular were tasked with taking notes during discussions and reporting back to the assembled participants a brief summary of points discussed. The presentations and breakout sessions were divided into five topic areas: "Challenges in Biorisk Management," "Risk Assessment and Mitigation Measures," "Biorisk Management System Performance," "Training," and "National Oversight and Regulations." The topics and questions were chosen by the organizers through consultation with US Government sponsors. The Chattham House Rule on non-attribution was in effect during question and answer periods and breakout session discussions.

\section{Presentations}

\section{Day 1}

\section{Opening}

The workshop began with a series of introductions by the organizers, hosts, and sponsors of the event, beginning with Dr. Jennifer Gaudioso of Sandia National Laboratories in the United States. Sandia National Laboratories' International Biological Threat Reduction Program organized the workshop on behalf of its US Government sponsors, and Dr. Gaudioso provided logistical details on the workshop's 
structure and rules, including an explanation of the Chatham House rule on non-attribution, intended to foster more honest and free discussion.

Dr. Gaudioso's initial logistical remarks were followed by welcoming remarks by Prof. Dr. Huseyin Avni Oktem of the Turkish Biotechnology Association, who welcomed participants to the city of Istanbul and to the Republic of Turkey. He stressed the importance of this meeting on biorisk management to the world, the region, and his country in particular, in light of new Turkish legislation on biorisk and recent phenomenal growth in the country's biotechnology sector. He invited participants to attend Turkey's hosting of the European Congress on Biotechnology in September of 2012.

Lastly, Jennifer Bae of the US Department of State's Biosecurity Engagement Program also welcomed participants on behalf of the US sponsors of the workshop, and provided context for the meeting from the perspective of the United States. The US Department of State Biosecurity Engagement Program (BEP) and the US Department of Defense Cooperative Biological Engagement Program (CBEP) are both active in efforts to reduce biological threats around the world, in particular through three pillars of action: laboratory biorisk management (biosafety and biosecurity), cooperative research and development, and disease detection and control. In the spirit of promoting biosafety and biosecurity around the world, BEP and CBEP worked together to jointly sponsor the International Perspectives on Mitigating Laboratory Biorisk workshop with an aim, as stated by Ms. Bae, to promote "a frank and honest discussion about the issues surrounding biorisk management, both in the laboratory and at the national and international policy levels." Ms. Bae related the US Government's large and growing interest in tackling "naturally occurring, accidental" and "intentional" biological threats through cooperation with partners around the world, in the spirit of President Obama's National Strategy for Countering Biological Threats presented at the Biological Weapons Convention Annual Meeting in Geneva in December of 2009. The workshop in Turkey was a part of that effort and its results would help inform higher level policy meetings such as the Biological Weapons Convention. Ms. Bae proceeded to discuss the Convention and its quinquennial Review Conference process, as well as the yearly intersessional process which focused on different topics of interest to States Parties. As countries are just now beginning to consider the Convention's Seventh Review Conference due in 2011, issues of biosafety and biosecurity are likely to form a part of new intersessional meetings, and results from workshops such as International Perspectives on Mitigating Laboratory Biorisk would help determine what some of those specific issues should and would be. Ms. Bae concluded by requesting participants to the workshop, as scientists and technical experts in the field who will be impacted by policy proceedings at the Convention, to consider what they would like to see discussed at meetings, how they would like to see policy shaped in the future, and to contribute to the International Perspectives workshop with these ideas.

\section{Session 1 - Challenges in Laboratory Biorisk Management}

After the welcoming remarks, the workshop opened with two presentations on "Challenges in Laboratory Biorisk Management," providing different perspectives from two respected members of the field. The first presentation was conducted by Dr. Uwe Mueller-Doblies of the Pirbright Institute for 
Animal Health in the United Kingdom. Dr. Mueller-Doblies has responsibility over biorisk management at Pirbright, dealing with risks associated with animal pathogen and disease research. Foot and Mouth Disease in particular has had a detrimental economic effect on the United Kingdom in the last decade, and the study of the disease and the virus that causes it is one of the Institute's important responsibilities. One recent success of the Institute has been its role in helping eradicate rinderpest, as well as its assistance in global surveillance of animal disease. The identification of the Pirbright complex, composed of the Institute for Animal Health as well as a facility operated by vaccine manufacturer Merial, as the source of the 2007 FMD outbreak in the United Kingdom underlined the importance of successful containment and management of biological risks.

Dr. Uwe-Mueller described several lessons that were learned from the incident. The first was the extreme importance of properly managing public perception, which is not easy for scientists or institutional managers to do because of intrinsic differences in outlook and understanding between them and the public at large. Also, the incident led to a realization that those with the duty to manage risks always face deep challenges whether or not there is an incident; they can often feel as if they are in a no-win situation. Business continuity, it was realized, depends on an ability to demonstrate compliance and adequate control of risks; however, there is generally a lack of scientific data that can demonstrate that controls are adequate, and this represents an important problem. The economic dimension of a release was seen as being extremely important, influencing the availability of resources and exerting different sorts of pressures. And finally, an incident such as the 2007 outbreak had a large regulatory impact on the facility and on the country, whether or not such regulations were necessarily warranted or appropriate.

Dr. Mueller-Doblies moved on to discuss the regulatory approach to biorisk management in the United Kingdom and, by extension, at the Pirbright Institute in the context of the Piper-Alpha oil-rig incident of 1988. This event led to a general reworking of the management of risk in the country towards a "safety case approach." The safety case approach is based on setting safety goals at the regulatory level and leaving operators to do what they must to reach those goals. The burden of risk management thus shifts from the regulator to the operator. With regard to Pirbright, this approach has led to the establishment of an ultimate safety goal of at most one consequential release of pathogen every 500 years. Techniques to effectively quantify biological risk in this manner are under development but are still far away. The ultimate objective is to be able to declare that a particular package of engineering and procedural controls gives an institute one incident in 500 years. Dr. Uwe-Mueller mentioned that at Pirbright, laboratory biosecurity controls are very much written by regulations and not by risk assessments, although in many cases measures determined to be necessary by biosafety risk assessments and intended as measures for biosafety and containment already met the requirements of biosecurity regulations. Among the various costs of security and safety measures at the Institute, calculated to perform cost-benefit analyses, were the blockage of legitimate work due to restrictions and thus a reduced positive impact on society from the laboratories. Dr. Mueller-Doblies concluded with a discussion on improvements slated for the Institute and the importance of the sustainability of measures and system performance. 
The second presentation of the morning was given by Dr. Ara Tahmassian of Boston University in the United States. Dr. Tahmassian began his presentation with a description of his work in charge of biosafety and biosecurity at the National Emerging Infectious Diseases Laboratory (NEIDL), a 196,000 square foot facility located in the urban center of Boston, Massachusetts. Due to its urban location and concerns from the neighboring community, achieving the highest standards in community and laboratory safety and security became one of NEIDL's three core missions. The approach to fulfill that mission has been to incorporate safety and security as integral parts of the institution's operations and culture. The initial suitability of personnel for work for NEIDL was seen as simply the starting point in the Laboratory's personnel reliability program, and continuous monitoring of employees was determined necessary to ensure these did not come to represent safety and security concerns. This sort of policy required a cultural shift among personnel, transforming sentiments regarding the monitoring policy from outright hostility at the notion of spying on fellow workers, to acceptance of such policies as necessary for safety and security.

Dr. Tahmassian described the access control system at NEIDL, including different methods for verifying identity (identity cards, iris scanners) and detection of dangerous items ("sniffers," x-ray detectors), how access for different personnel to different areas of the facility was determined, how escorted and nonescorted access policy was designed, and the policy of continuous monitoring of and by personnel. He regarded physical security steps as easy; the difficulty was in achieving the necessary cultural shift. The importance of how one frames policy was discussed; effective communication was seen as key for achieving safety and security objectives. Personnel were more willing to accept continuous monitoring and other measures if these were framed in terms of safety concerns as opposed to security ones, although in the end both needs were served. Safety, security, and public health were seen as being intricately interrelated. A poor employee could represent a safety and a security risk, either of which could then affect the community and public health. Dr. Tahmassian concluded that appropriate training and engagement was critical for improving skills and achieving the necessary cultural change.

Dr. Gary Burns of AstraZeneca Pharmaceuticals followed Dr. Tahmassian's presentation with an introduction to the CEN Workshop Agreement 15793 Laboratory Biorisk Management Standard. Dr. Burns acted as a vice chair for the workshop that later evolved into the CEN process. He began his presentation with a general question: why develop a biorisk management standard in the first place? He noted that although there already were standards, guidelines, and codes available prior to the CWA document, these tended to be technical and prescriptive and often had a national or regional focus. Dr. Burns discussed the process of developing the CWA Standard, including meetings in 2005 between members of different international biosafety associations as well as intergovernmental organizations such as the WHO. During these meetings, existing guiding documents were reviewed and agreement was reached on the development of a performance-based, international standard that would drive improvements in risk management. These improvements were particularly important for areas of the world with less well-developed regulatory frameworks, and a new standard would provide assurance to the international community of stakeholders that laboratory risks were being effectively managed. International funding for this process was approved, and a series of meetings held in Brussels and 
Boston in 2007, along with public consultations, led to the publishing of the Standard in February of 2008.

The Standard addressed both biosafety and biosecurity concerns under the unified concept of biorisk. The Standard was also performance-based and risk-based, and contained definitions, requirements, and notes as guidance to assist in implementation. The Standard's approach allows various levels of control to be implemented based on assessed levels of risk, and it's capable of being adopted for use in any particular laboratory, whatever the situation and risk level. An important point stressed by Dr. Burns was that the Standard was completely voluntary and was not meant to replace or substitute for national and international regulations, but rather complement them. It utilizes the plan-do-review-act cycle like other management standards. Under it, a laboratory or institution's management is made responsible for risks and are tasked with ensuring these are managed properly.

Dr. Burns noted that since its release, the Standard has been downloaded more times than any other standard in the CEN library, in particular after the WHO guidance on laboratory work with H1N1 in 2009 listed the Standard as one of its essential reference materials. It was been used as an input in UK regulations, and Germany, despite its delegates' initial misgivings, has seen the Standard implemented in more locations within its borders than any other. Dr. Burns discussed next steps for the Standard, as a review process is due in 2011, along with ongoing development of a guidance document on implementation (WS 55), a standard on Biosafety Professional Competency (WS 53), and the development of an accreditation and certification process. Dr. Burns concluded by stating that the Laboratory Biorisk Management Standard had been developed by the user community for the user community, had international application, addressed biorisks holistically, and could be used to demonstrate responsible management of biological risks.

Dr. Alberto Díaz Quiñonez of the Mexican Biosafety Association followed Dr. Burns' presentation by discussing the management of change in institutions and the implementation of laboratory biorisk management in his country. He began with a description of the health care system in Mexico, in particular the national social security system, and its responsibilities in the sphere of public health, such as in the diagnostics and tracking of infectious disease. After the pandemic influenza outbreak of 2009, the health system adapted by retooling an existing public laboratory as a core facility from which standards in diagnostics and handling of specimens were developed and disseminated across the country. This was accompanied with the development of a new public health laboratory network based on existing laboratories that would serve as an appropriate response to the country's needs in times of crisis. The creation of such a network required institutional change.

Dr. Quiñonez provided an analysis of the process of institutional change: what can induce it (events such as the H1N1 pandemic, for example), whether change is managed in a proactive or reactive way, whether it results in a transition or a transformation, and what that change involves in terms of the state of people's mentalities and psychology. One primary goal in the management of change within Mexico's laboratory network was to reduce turmoil to a minimum and improve state performance in a significant way. Dr. Quiñonez described the process of transitioning the laboratory from scientific research in an independent operational environment to diagnostic work within a network of other, 
similarly tasked laboratories. The process of transition and change prompted by the events of 2009 is still ongoing. Among the core laboratory's new institutional responsibilities is working to update algorithms for the electronic surveillance of disease, as well as to serve as a nucleus for laboratory training, including biorisk management training, in the country. Institutions in Mexico have been involved in a series of collaborations with outside experts from the United States and Canada to help train personnel in biorisk management, and a multi-step training curriculum has been developed to increase human capacity in this area. Furthermore, institutions as well as interested individuals in the field have been helping influence national guidelines and norms in biosafety and biosecurity through the work of the Mexican Biosafety Association.

\section{Breakout Session 1 - Challenges in Laboratory Biorisk Management}

\section{Summary}

Prior to Breakout Session 1, the rules were reiterated from earlier in the day as described above. The use of the Chatham House Rule was intended to encourage the open and honest discussion that is necessary to understand the true nature of the challenges and opportunities that can be found in a Biorisk Management System. The goal of the first breakout session was to set the groundwork for discussions throughout the rest of the workshop. To do this, the questions each group was tasked with answering revolved around the challenges found within laboratory biorisk, what a Biorisk Management System is, the opportunities that such a system can provide, and the roles and responsibilities of institutions for properly managing biorisk.

\section{Breakout Session 1}

The first question that was given to the participants was: What challenges exist in managing biological risk in laboratories? There was a broad range of responses given to this answer, discussing difficulties on the broad, governmental level to the individual laboratory level. The greatest challenge seen by the participants was that of financial constraints. Facilities cannot properly implement biorisk mitigation strategies if there is no funding to do so. This challenge coincided with several others, including the need for government buy-in. Higher authorities need to accept, understand, value, and support biorisk management, and incorporate it into policy documents. Governments also cannot address this issue unsystematically. Doing so will result in multiple agencies and ministries acting as oversight bodies. This creates confusion as to regulations and compliance if the different ministries do not coordinate and harmonize their requirements. Currently, in many countries, there is no oversight to speak of, which can lead to similar problems because lack of guidance leads to individual efforts to mitigate the risks. On the individual laboratory and facility level, engagement and buy-in from the workforce is necessary. Without buy-in from the workforce, managing the biorisks will be increasingly difficult because of constant pushback. Even with buy-in, assessing the risk is difficult because there is little data and awareness to aid in establishing appropriate risk levels that are acceptable. This is working under the idea that there is no such thing as creating a zero risk situation, and each individual laboratory must evaluate their situation and what their level of acceptable risk should be. Due to the uniqueness of each laboratory, there is no "one size fits all" solution that can be uniformly applied to mitigate biorisk. This 
is not only true on an international scale, where there are varying degrees of laboratory biosafety and biosecurity in place, but on a domestic scale as well. What type of research being conducted within a laboratory, the pathogens being used, and a whole host of other factors go into creating individual solutions to biorisk. Once a biorisk management system is in place, there are still constant challenges that are faced. These systems are not static, therefore there needs to be constant maintenance and continuity. This allows for the continued improvement and sustainability of a program. Individuals who are managing and working to mitigate biorisk must also have the competencies necessary to perform their duties to the highest level.

The second question asked of the groups was: What is a Laboratory Biorisk Management System? One group defined a Laboratory Biorisk Management System as "an integrated systematic process of management support to adopt processes and tools to uniformly and comparatively assess risks, adopt mitigation techniques, employ tools, and monitor and improve performance of results." It was further added that it must be a risk-based and quality controlled management system that must employ a dynamic assessment methodology so that it can continually adapt to new risks. One key was the understanding that each country can have different requirements, like individual laboratories have different requirements for how a Laboratory Biorisk Management System is implemented. Discussions then moved to the CEN Standard (CWA 15793) and its possible use as a biorisk management framework. The CWA must be scaled appropriately and then implemented in ways to fill the gaps that are unique to each situation. In some cases the Standard is too comprehensive to meet local requirements. Because of CWA 15793, there is no need to start from scratch in building a biorisk management system; the Standard can be used as a starting place and reduced to create a streamlined management system appropriate to the situation and allow for the conservation of limited resources.

The next question was: How can such a system help overcome some of these challenges? The key to this question was that the presence of a management system can allow for the changing of the thought process. By doing this, it allows for the incorporation of safety and security into the everyday actions of the workforce. This will be done by raising awareness and buy-in for the concepts put for in the management system. Included in these concepts are continual improvement and assessment of risks. In showing this continual improvement and assessment, senior management can see programmatic connections which can in turn increase the funding of biorisk related activities. Raising awareness in the community of biorisk issues and mitigation strategies can also be a crucial step in transparency to help gain support for the work being done within "their backyard." Having a Laboratory Biorisk Management System can also help institutions create standards for mitigating biorisk. It will allow for comparisons to be made between institutions. Such a system can aid in establishing competency indicators and rules for the general workforce as well as for biosafety professionals. A biorisk management system can help to harmonize the transfer of risk, responsibility and accountability within the organization to its management as well as its workforce, allowing the latter to take ownership of the tasks they are performing and the safety and security of the research. With this standardization and the emergence of consistencies, a management system will allow for the exchange of national experiences, technical information on new and existing equipment, information on design and construction of facilities, and information on outbreaks and other emergencies, including the proper responses to such emergencies. 
Finally, having a biorisk management system in place allows for the prioritization of needs and in turn help show where improvements have been gained to garner further support from within the institution and from without.

The fourth question put to the groups was: What institutional roles and responsibilities are necessary for personnel to properly manage risk? This response to this question split relevant stakeholders into three responsible groups: the international community, national governments, and institutional management. The international community is responsible for advocating support for the implementation, maintenance, and modification of biorisk management systems. The role of the national governments, on the other hand, is not only to advocate for a system but also to allocate resources to implement and sustain the system. Institutional management must specify within their policy documents the need for safety, security, and accountability. They must also understand the difference between responsibility and accountability. As management they can delegate responsibility for the management system, but accountability for the system will always remain at the top levels. The groups also identified issues and concerns that must be addressed by various stakeholders. Knowing the ultimate authority in each country, or knowing whether there was no single authority but a combination of various stakeholders, was seen as critical. With combined biosafety and biosecurity, the institutional roles and responsibilities fall into one place, but when things go wrong in reality, who is culpable? While a $3^{\text {rd }}$ party certification process for laboratories may be necessary, who are those authorized and competent to license the system? Other concerns included the frequent funding difficulties and managerial commitment to the biorisk management process, as well as the lack of a proper distribution of responsibility for biorisks across an institution.

The final question asked to the group in the first breakout session was: What are some opportunities and obstacles that arise as a result of implementing a biorisk management system? The groups felt opportunities had been covered above (see the third question) and decided to focus the remaining time on the obstacles that arise through implementation. There were four categories of obstacles seen to arise from implementation of a biorisk management system: cultural, those concerned with oversight, those concerned with funding and implementation, and those concerned with expertise. The need for expertise is critical in each instance for creating and implementing a biorisk management system. Currently, there are not enough experts within any country who can take the lead in developing these systems on an institution-by-institution basis. Culturally, the uniqueness of each country's customs and local laboratory practices can complicate how managers are able to implement a management system. A further challenge is the language barrier that many must overcome to understand, let alone implement, existing documents such as CWA 15793. Even with initiatives like the translation of the CWA 15793 document into local languages, problems arise when particular terms in the original language are missing in or difficult to translate into a local one. In terms of oversight, questions remain as to who will review and oversee international documents like the CWA 15793 to ensure they are updated as necessary. This process of oversight must remain a collective effort by those who have a stake in and are affected by the Standard, but coordinating this collective effort can be a challenge. Further, the Standard must remain performance-based and not chase specific targets. Other concerns revolved around the CWA 15793 potentially becoming a de facto national standard without an 
evaluation as to its appropriateness for specific situations. Finally, as has been discussed above, there are difficulties in creating a solid funding stream for a biorisk management system. As the system is implemented, the benefits gained must be clearly documented to allow for justification of budgets and necessary resources. Implementation is difficult because it cannot be a system that follows targets but must focus on underlying concepts that determine those targets. Because of this and the need for continual improvement, there is no point at which a biorisk management system has ever completed its tasks.

\section{Session 2 - Risk Assessment and Mitigation Measures}

Afternoon presentations focused on the topic of "Risk Assessment and Mitigation Measures." The first presentation, on risk assessment tools and applications, was conducted by Dr. Mika Shigematsu of the Japanese National Institute of Infectious Diseases. Dr. Shigematsu began her presentation broadly by discussing the notion of biosafety and biosecurity unifying into the single concept of biorisk. She continued with a discussion on the importance of the risk assessment process and how assessments must be combined with actions for risks to be properly mitigated. Several practical principles of assessing risk were provided: defining the problem you are attempting to solve or the question you are attempting to answer with the assessment, utilizing as simple a method as possible for assessing risk, requiring those conducting risk assessments to be explicit about uncertainties, and realizing risk assessments can incorporate one or more approaches.

Dr. Shigematsu proceeded to discuss different kinds of tools available to those charged with assessing risk. Guidelines and manuals were important, she said, but she mentioned that international documents, mostly available in English, may be difficult for a non-native speaker to understand. She then introduced the Biosafety RAM tool, the result of an international collaborative project that seeks to simplify the assessment process for biological laboratories. This computerized tool involves completing a 20-30 minute questionnaire and, based on the answers, produces results that help identify and prioritize risks in the laboratory. Users can then, depending on their level of acceptance of risk, determine which risks are acceptable or unacceptable in their laboratory and act accordingly. A version for biosecurity assessments using the same methodology is also available. One point mentioned was the importance of perception in the assessment of risk. Assessments done by managers and those done by principal investigators can be very different because managers and investigators have different perspectives, levels of knowledge, and responsibilities. As a result, the person conducting the assessment becomes an important factor in the eventual results, as well as in the mitigation measures that are subsequently taken. Dr. Shigematsu mentioned that it can often be difficult to explain to an institution's management that there is no such thing as zero risk, and so finding effective ways to explain and communicate necessary information and concepts to the administrative structure above becomes very important.

Mr. Paul Langevin of Merrick \& Company spoke next, discussing engineered and procedural solutions for laboratory biorisk management. He mentioned the engineering perspective on managing biorisks and how it is based on looking at the world through measurements and equations and on the 
achievement of particular end-states through proven technology and knowledge. Mr. Langevin brought attention to the disconnection that often exists between biosafety and biosecurity communities, institutional administrators, and providers of engineering solutions. In certain parts of the developed world, there has been a tendency towards "overengineering," or the application of engineering solutions to problems that may not in fact be real, in an attempt to achieve the perception of a high level of safety or security. Many of these solutions may not be consistent in their application or otherwise rationally thought out for a particular situation, but are implemented regardless in an attempt to make laboratories appear as safe and secure as possible. Such tendencies have led to more and more expensive laboratories that may overlook simpler solutions and not address risks properly. Engineering solutions can be extremely effective and very often necessary for reducing risks in laboratories, allowing institutions to achieve safety and security standards that would otherwise be impossible. But, they must be applied in a rational and consistent manner, proportional to the situation at hand and risk level assessed. Mr. Langevin suggested improving risk analysis and conducting additional research as means for achieving a better assessment of actual risk, and thus a better assessment of actual needs, to properly address safety and security problems in laboratories. Mr. Langevin also suggested there was a need for strengthening biosafety and bio-containment guidelines in order to simplify the application of engineering controls and better approach the process of risk reduction.

\section{Breakout Session 2 - Risk Assessment and Mitigation Measures}

\section{Summary}

Breakout session questions were divided in two areas: those focusing on the risk assessment process and others on mitigation measures. General conclusions included, once more, the difficulty of assessing risk in the laboratory, the connection between risk assessment and programmatic mitigation, advantages and disadvantages of engineering solutions to mitigate risk versus emphases on training, building the competence of a laboratory workforce, and others.

\section{Breakout Session 2a - Risk Assessment}

The first question asked in this breakout session was: What is the purpose of a risk assessment? The answers participants considered included assessment of the situation in the laboratory in order to create an effective action plan to mitigate risks. Assessment of the situation in a laboratory requires a setting of the scope of the assessment, understanding whatever hazards exist in the laboratory, and being able to determine, perhaps roughly, the likelihood of those hazards manifesting themselves. The action plan stemming from this assessment of the situation would require a prioritization of risks, mitigation techniques, and utilization of available funding as well as human resources. There was some debate as to the timing of risk assessment within the biorisk management process, with some considering it important to conduct risk assessments repeatedly as things changed or failed.

The next question considered how laboratory risk was normally assessed in institutions in the participants' native countries. Some participants remarked that there was no method for assessment in their country, whereas others stated the risk assessment process was very new in their countries. There was generally a diversity of methods mentioned, including segregation of pathogens and toxins into risk 
groups, depending on institutional biosafety committees, some sort of national or informal process for certifying containment laboratories that included assessments of risks, and others whose only process or legislation depended on assessment of risks posed by genetically modified organisms. In most cases, the risk assessment process was homegrown for each institution. Some countries could rely on limited regulatory guidance from above.

The next question regarded the difficulty of conducting risk assessments and why it should or should not be as difficult as it was generally regarded. Participants said laboratory workers and institutional managers alike were generally hesitant to document the existence of uncertainty or risks. It was also seen to be rather difficult to determine whether a risk was acceptable or unacceptable. It was noted that most high-risk pathogens get the greatest focus even though accidents are more frequent in BSL2 laboratories. It was also noted that quantitative analysis was not always necessary for conducting risk assessments; qualitative assessments were conducted often enough, and quantitative analyses needed to be justified on the basis of prior, qualitative analyses. In fact, quantitative analyses, although desirable in many cases, were seen to also cause an increase in uncertainty, potentially de-legitimizing results and having negative effects on the assessment process. It was recognized that risk assessments could not be performed in isolation; they require human and financial resources. A lack of trained and experienced staff to conduct and interpret risk assessments was a recognized problem in most institutions, compounded by the lack of widely adopted, formal risk assessment methodologies. A need was seen to integrate biorisk management ideas into professional curricula as well as textbooks in order to increase awareness and knowledge on assessment, as well as management processes. Another difficulty with risk assessments was the acknowledged lack of viable information. There is little data on laboratory-acquired infections, for example, and so seemingly little upon which to base one's assessments of risk.

The final question of the session regarded the advantages of conducting risk assessments in a robust, reproducible, and transparent manner. It was noted that if risk assessments were conducted in such a manner, those conducting the assessments would be more likely to trust their work, take ownership of it, and be more confident in their understanding of risk. Transparency, it was noted, allows for ease in explaining the results of the risk assessment to others and others trusting the validity of those results. Risk assessments that are robust, reproducible, and transparent would need to be based on knowledge rather than perceptions and on demonstration rather than subjective interpretation. Such a risk assessment methodology would also provide a basis for effective communication. Management would be more confident in the allocation of resources, the work force would better understand the necessity of mitigation, and the public would be aware of real risks rather than perceptions borne of fear and irrationality. A scientific methodology for the assessment of risk excludes the human factor of uncertainty, and transparency helps ensure a more comprehensive action plan is adopted.

\section{Breakout Session $2 b$ - Risk Mitigation}

The first topic of this breakout session regarded how the assessment of risk was connected to strategies for improving safety and security in laboratories. The first point noted was that the risk assessment process helps initiate or support a culture of biosafety and biosecurity. Risk assessment was regarded as having to be the first step in any process of risk mitigation; it tells the assessor where the laboratory is in 
regard to its risks and therefore is essential in determining what must be done to arrive at an improved state of affairs. It was seen that risk assessments needed to be a team effort in order for those that would be implementing risk mitigation measures based on the assessment to be committed to the process and understand the underlying rationale for changes. Cooperation on these activities helps create awareness and balance perceptions on what is occurring in the laboratory. The risk assessment, it was noted, is connected to all functions of the lab. The right competencies were seen to be required of the personnel assessing risk as well as the personnel interpreting the results of the risk assessment in order to decide on acceptable and unacceptable risk and develop appropriate and effective mitigation strategies. Repetition of the risk assessment process at some level was seen to be necessary after every new implementation of a new procedure or operation in the laboratory. It was also seen that in the process of translating risk assessment into risk mitigation, clarity in the process and in which personnel have responsibility over what are important. Risk assessment, it was repeated, creates awareness of risks around the laboratory and allows for a determination by management on the acceptability of those risks. Proper assessment and decisions on acceptability and unacceptability of risk allow management to determine appropriate risk mitigation strategies.

The next question regarded the factors that could be considered important for the successful implementation of a risk mitigation strategy. The first factor mentioned by participants was the level of funding and the support management provides to the mitigation strategy and to ongoing capacity building, echoing a theme present throughout other breakout sessions and the conference as a whole. A management commitment to responsibility and accountability was seen as crucial, and budget allocation was regarded as needing to be based on a hierarchy of mitigation controls. A proper determination of the practicality, applicability, consistency, reliability, flexibility, and adaptability of mitigation measures was seen as necessary, which in turn required a thorough understanding of the agents and the procedures involved. Necessary human factors included the knowledge, skill, and expertise level of the workforce as well as their attitudes and commitment to the mitigation strategy. It was noted that the ability to check on the performance of implemented mitigation measures through the development of quantitative methods could be desirable. Communication as a factor was also important; internal communication between those with knowledge and those charged with making decisions, as well as external communication in terms of educating outsiders and forging acceptance of the effectiveness of mitigation strategies, were both seen as crucial for effective implementation. Finally, redundancy and room for error built in to the overall mitigation strategy was seen as important to limit the potential uncertainties caused by the human factor.

The next question of the breakout session was how decisions on the cost versus effectiveness of different mitigation measures should be made. The first point mentioned was that it was necessary to identify the risk threshold in order to set it as the bar that influences decision-making. That is, it was seen as necessary to determine the level beyond which risk was unacceptable, and decide whether it was reasonable or cost-effective to reduce risks above that level to a point below that level. That would determine whether or not a risk would end up being mitigated. Another point mentioned was the importance of regular monitoring to determine the effectiveness of mitigation measures and thus be able to ascertain whether mitigation of a particular risk in a particular way is worth the effort. 
Consideration of the sustainability of any given design was seen as important; a measure of sustainability as a percentage of the initial capital outlay was suggested as a possible metric to compare the costs of different measures or over-all strategies. Training, reporting, and incident recording were seen as allowing continuous improvement. Another issue mentioned was that of scalability; the more one can regionalize, find common strategies with other laboratories, and make common purchases, for example, the better from a cost and efficiency standpoint for the individual laboratory. Every risk, it was noted, has several possible mitigation solutions. Cases must be evaluated individually and determinations made based on available resources.

The last question of the session regarded the advantages and disadvantages of training and procedures versus reliance on engineering solutions. One participant noted that the two seemed opposites; what may be an advantage for one may be a disadvantage to the other. Training has a higher recurrence cost, it was noted, whereas engineering solutions are relatively stable once initial costs are incurred. The transferability of skills is an advantage that training has over engineering controls; some engineering solutions can become obsolete after installation. However, it was noted that newer engineering systems offer greater built-in flexibility allowing them to be reconfigured for multiple tasks and thus extending their utility and viability longer than older systems. Reliance on engineering solutions can result in workforce complacency. On the other hand, engineering systems provide hard data on their functioning and reliability that can be measured and trusted in a way that human performance measures cannot. Low-tech solutions are often best, and highly reliable procedures can often outperform engineering controls. However, engineering controls can often achieve conditions of containment and control that are otherwise impossible through procedures or any other method. The choice between different mitigation measures depends on the situation: the performance and cost of available engineering controls, as well as the level of competence in procedures and maintenance achieved by the workforce. In many situations where resources for expensive capital investments are low, a rigorous training program can substitute for engineering safety systems. There was a general recognition that a mix of engineering controls, training, and procedures was always needed. It was a matter of ascertaining resources and capabilities and determining the proper mix of the three.

Regardless of the mix, continual monitoring, assessment, and maintenance were always necessary for all three systemic components, and a proper consideration of feedback signals was needed to maintain performance and thus effective mitigation of risks. 


\section{Day 2}

The second day of the workshop began with summaries of breakout session discussions by session rapporteurs, all members of the Sandia National Laboratories team. The morning's focus then shifted to presentations on "Biorisk Management System Performance" and in the afternoon moved on to discussions on "Training."

\section{Session 3 - Biorisk Management System Performance}

The first presentation of the day was offered by Dr. Se Thoe Su Yun of the Singapore Ministry of Health, who focused on the use of laboratory audits and national inspections in the centralized system for laboratory biorisk management employed by the Republic of Singapore. The system arose from the country's Biological Agents and Toxins Act of 2005, which aims "to prohibit or otherwise regulate the possession, use, import, transshipment, transfer and transportation of biological agents, inactivated biological agents and toxins" and "to provide for safe practices in the handling of such biological agents and toxins." The Act requires high-risk biological agents, as distributed within two risk groups, RG3 and RG4 respectively, to be handled in a "certified BSL-3 facility." The certification process for a laboratory under the Act covers a wide scope, which can be divided into three general areas: engineering controls, administrative controls, and science or procedural and practices-based controls. The certification process utilizes a checklist expanded from the WHO Laboratory Biosafety Manual's ( $3^{\text {rd }}$ Edition) safety checklist, with engineering verification and augmentation of material control and accountability, personnel screening, training, emergency drills, and risk assessment records added. Certification is conducted by a team consisting of a qualified biosafety professional and an engineer.

Dr. Se Thoe provided an overview of the certification process, which begins with an on-site walkthrough by the certification team to conduct a visual inspection of engineering spaces and the laboratories themselves. This is accompanied, or sometimes preceded by, a document review of laboratory programs; standard operating procedures; and records for risk assessments, training, equipment maintenance, personnel entry and exit, and incidents and inventories, among others. The next step involves interviewing personnel on their knowledge of agents, risks, and practices and procedures, as well as practical demonstrations by personnel of donning and doffing PPE and rehearsals of standard operating procedures. New staff is also tested, and emergency drills are conducted to ensure proper performance. The final process involves testing and challenging engineering systems to ensure airhandling and containment equipment is functioning properly. The length of the process can be variable, between a day and several weeks to even months, depending on the laboratory, certifier, and the level of non-compliance. A certificate is valid for one year or until design and structural changes are made to the facility.

Dr. Se Thoe then provided an overview of a system audit process in the form of yearly joint-emergency response drills conducted between laboratories, the Ministry of Health, and the Singapore Civil Defense Force. Scenarios are planned by the laboratories jointly with the Ministry of Health, and on the day of the drill, labs play out scenarios to which the Civil Defense Forces must respond. Scenarios may simulate fires, unconscious persons, or other problems, including, more recently, biosecurity incidents. 
The Ministry of Health will audit the drill and ensure communications within the laboratory and between the laboratory and the Singapore Civil Defense Force occur as they should. The Ministry of Health will also audit the Singapore Civil Defense Force's performance in responding. Concluding her presentation, Dr. Se Thoe expressed her country's desire to continue improving their national biorisk system through the development of a more comprehensive scheme for laboratory certification which covered both biosafety and biosecurity more effectively, as well as building further capacity in lab certification through development of additional local expertise, and increasing experience-sharing among different stakeholders.

The following presentation was conducted by Dr. Paul Huntly, a consultant based in Singapore who works for Det Norske Veritas (DNV). Dr. Huntly discussed international inspections of laboratories in the context of the CWA 15793 Biorisk Management Standard. He began with an overview of DNV's Biorisk Management group, for which Dr. Huntly is responsible, and DNV's role as one of the organizations that originally helped develop the concept of biorisk. DNV has been involved with a variety of industries in the development of management standards and protocols, and attempted to do the same for biological laboratories. Unfortunately, the absence of a standard in the field was found to be problematic. Discussions by several stakeholders, including DNV, on the development of a biorisk management standard began in 2004 and culminated with the CWA 15793 document in 2008. The underlying rationale for the CWA Standard derived from the assertion that most accidents and incidents in a laboratory were due primarily to failures in management. According to Dr. Huntly, management must be seen to be responsible for providing assurances that risk is managed effectively and proportionately with adequate and, in turn, proportionate controls. All relevant staff should understand risk as it applies to their work and be in a certain position to exert control over that risk. This requires a system to be in place to identify and manage risks on an ongoing basis. The CWA Standard helps do this in a standard way. According to Dr. Huntly, the CWA document allows biorisk management strategies to be customized to the particular situations of different laboratories and in different countries, making it possible for management solutions to be achievable in the first place and maintained into the future. The Standard is international, helping assuage fears that it may not applicable in one or another country, and is proportional, allowing for mitigation measures to be applied flexibly as needed and as appropriate, whatever the situation, based on a laboratory or institution's own performance goals.

Dr. Huntly proceeded by discussing the risk assessment process in the context of the CWA Standard. The assessment process, like any process, needs a plan and a scope, and it is important to understand what question the assessment is indeed trying to answer. Because the CWA Standard does not discuss particular engineering solutions or local regulatory requirements, an assessment team using the Standard as a guide must understand what the laboratory or institution is attempting to do through which methods and bring with them whatever technical knowledge would be necessary to successfully conduct that assessment. Assessing risk requires interviewing workers and management in order to understand the elements that should be in place, and then walking through a facility and reviewing paperwork and protocols. Dr. Huntly described how risk assessments have been done in many industries for many years, and that tools were available to aid in this process. Quantification is not necessarily needed and the process can in fact be easier than some may believe. The CWA is not 
primarily about certification, Dr. Huntly said, but was about putting controls in place. Certification is related to controls but is not the same thing.

Moving beyond assessments into frameworks for biorisk management systems, Dr. Huntly mentioned that these should be looked at, but refrained from recommending they become law. He said they could be promoted through other methods, such as making adoption of a biorisk management system a prerequisite for funding. He also stressed the differences between training and competence, underlining the fact that a trained person is not necessarily competent, and demonstrable competence should be a goal of any biorisk management system. He said international collaboration in all these areas should be promoted. Concluding his presentation, Dr. Huntly stated that the CWA Standard formed an excellent framework within which to assess laboratories and related environments, but that the Standard was only one part of assessment and that the Standard itself was primarily about improving performance, not about certification. He hoped the Standard in its upcoming review would be renewed again.

\section{Breakout Session 3 - Biorisk Management System Performance}

\section{Summary}

Breakout sessions focused on incident reporting and inspections or audits as mechanisms. to ensure continuity of performance in biorisk management systems. Discussions centered on the reliability of reporting, zero-penalty policies to encourage compliance, competence in personnel conducting inspections and audits, scope of monitoring and inspection, authority, review, and triggers for corrective action.

\section{Breakout Session $3 a$ - Incident Reporting}

The first question in this breakout session dealt with what constituted a safety or security incident and when such an incident should be reported. It was regarded that any variance or deviation from a management plan, policies, and procedures constituted a reportable event and that reportable events could be regarded either as accidents, incidents, or near misses. According to the CWA 15793 Biorisk Management Standard, an incident is an "event with potential for causing harm." Another suggested definition for the term "incident" was "any event impacting biosafety and biosecurity." It was noted that although all incidents could be reported, the timing of reporting depended on the severity and time-sensitive nature of the incident. Thus, some incidents would require immediate reporting. It was noted that it was particularly important for reporting mechanisms to be non-punitive in order to encourage self-reporting.

The next question considered in the session regarded the details that should be included in a report following a safety or security incident. It was regarded that the most important element of a report was that it should reflect "just the facts." That is, it should answer who, what, when, where and how. It was also important to record and report the initial response to the incident. Also, in the event of a security event, it was important to know the potential pathogens accessed and any background on the event that may be necessary, such as on the individual if the information was available, on the pathogens, and 
the security situation of the laboratory or installation. A clear and concise account of the incident was deemed rather important to prevent confusion.

The next question regarded institutional management and how it should review, assess, and act upon incident reports. The first point noted was that institutional management should first follow up with any staff health issues after an incident, as safety of personnel was seen as the most important immediate concern. Then, the report should be investigated in order to determine its accuracy and the full scope of the incident. Such an investigation should be undertaken as an honest evaluation that avoids pointing fingers, and there should be a non-punitive response. For this process to be successful, effective communication among all parties would be required. An analysis on root causes for the incident must also be mounted. Corrective action should then be undertaken, often as a time-limited contract between the laboratory and the safety office to ensure there is a commitment between the two parties to act and implement. Preventive action should also be implemented. After some time a review to ensure completion of corrective action and any necessary modification of program documents should be implemented. Lessons learned from the incident must also be reviewedand the incident must be communicated to all relevant internal parties, and should also be shared with the broader biosafety and biosecurity community. Lastly, tracking of trends, especially on near misses, should be performed in order to take preemptive action on potential issues and prevent future accidents.

The next topic covered was the factors that make an incident reporting system effective or ineffective. Many of these have already been mentioned. The first was that punitive measures after an incident are a disincentive towards reporting. Punitive measures could take the form of disciplinary action, stigmatization, and emergency response costs, among others. Also, it was seen that if the incident response process was long, complicated, or seen to be ineffective, it could be a further disincentive to reporting. Effective measures to improve a system include anonymous reporting, a clear understanding of reporting requirements and procedures, communication of lessons learned (thus demonstrating added value) and perhaps a parallel, informal process for handling certain sensitive incidents. One last point noted was that if one strives for perfection in one's incident reporting system, sometimes the result can be too complicated and less effective.

The final topic covered in this breakout session was a general question on other ways of measuring how well risk management systems are performing. Groups assigned questions regarding incident response systems considered other method for measuring performance to include institutional self-assessments such as internal audits and inspections; external assessments such as accreditations, government inspections and audits, and biosafety association reviews; the institution of annual reviews; open communication between technicians conducting the bulk of laboratory work and biosafety professionals and managers; drills; application and tracking of performance indicators, such as number of excursions from standard operating procedures, number of incidents, number of illnesses, among others; and measurement of risk versus costs, in order to check whether the correct issues are being attended to and prioritized in the proper manner. 


\section{Breakout Session $3 b$ - Inspections and Audits}

The first topic discussed in this breakout session was the difference between inspections and audits. There was in fact no clear consensus on the differences, though all agreed both were measures for verifying the correct functioning of the laboratory through checking by some authority. There was, however, disagreement on the details. Among the different types of inspections and audits, it was considered that important distinctions included whether there were internal versus external audits, those done by accrediting bodies versus legal bodies, and those that were mandatory versus voluntary. How institutions behaved depended on the types and frequencies of these audits and inspections. A variety of approaches was recognized around the world. Internal versus external inspectors and auditors were discussed, whether inspectors and auditors were from the private or public sectors, and what different interests and incentives each of these might have. Whether staff conducting inspections and audits was internal and local, which may or may not create conflicts of interest, or external and nonlocal was also discussed. The importance of the competency of those conducting inspections was raised because if one does not understand what one is inspecting, the inspection becomes difficult to take seriously at best and arbitrarily damaging at worst. In the end, it was noted that it was management's responsibility to ensure the institution is properly configured to handle necessary inspections and audits in whatever form that was required. A further note was discussed on the topic of third party "accreditation" of laboratories, as there have been some organizations around the world offering inspections and "certificates" suggesting such and such a laboratory was officially determined to be a BSL2 or BSL3, for example, when there is in fact no standard of what a BSL2 or BSL3 laboratory is and therefore no way to formally certify or validate a laboratory as a BSL2 or BSL3. This sort of inspection and its accompanying certificates are produced through a necessarily informal process and therefore, may not be as valuable as institutions may be led to believe by those conducting the inspections.

The next topic discussed regarded what sort of personnel should be responsible for conducting inspections and audits. The overarching point made was the importance of inspectors and auditors to be competent in performing their duties. It was noted that an incompetent inspector or auditor could cause a lot of damage to a laboratory and its legitimate work. Regulatory officials, accrediting bodies, internal audit committees, biosafety associations, and biosafety officers were all regarded as potentially having roles as inspectors and auditors of facilities. Special note was taken of internal staff as possible conflicts of interest that may affect the institutions and the validity or dependability of the inspection or auditing results. Important qualities thought to be required of inspectors and auditors included experience, expertise in both laboratory work and inspections, demonstrated competency through tests or programs, ability to communicate, open-mindedness, and flexibility within necessary constraints. The CEN Workshop 53 process for Biosafety Professional Competencies was mentioned as a development on the horizon in this area.

The next question in this breakout session dealt with what needed to be inspected and audited in a laboratory or institution, and in what manner should this process proceed. Among the areas participants thought it might be important to inspect and audit were documents including standard operating procedures, chains of custody, physical laboratories, facility engineering performance, security and safety plans, incident plans, waste management policy, personnel competencies, 
backgrounds, training records, roles and responsibilities, and current performance, among many others. How all these should be inspected, it was thought, depended on the objective of the inspection or audit. Whether the focus of the process was verification of compliance to certain standards or more to suggest improvements would have an important effect on how the inspection or audit would or should be carried out. It was noted that audits can be more unpredictable and therefore more uncomfortable; however, audits also tended to be improvement-oriented in nature, aimed at people, procedures, and infrastructure that pose the highest risks. For security measures, many participants saw that biosafety inspections mostly took care of biosecurity concerns, though there were indeed some areas of conflict. A question was asked: How does one inspect the state of awareness of personnel and the state of personnel responsibility? One possible method was for inspections and audits to include tests of personnel awareness of their knowledge and responsibility.

The next general guiding question of the breakout session dealt with how institutional management should review, assess and act upon the receipt of the results of inspections or audits. It was thought that firstly, management should recognize that running a laboratory was not a zero risk endeavor, something that was noted elsewhere as being something difficult to communicate to management at times. It was thought to be important to avoid a culture of non-reporting of accidents or incidents because that would leave one unprepared for inspections and audits as well as incidents and accidents that could occur in real life. It was noted that it was important for management to conduct root cause analysis on findings to understand the how and why of any failures or shortcomings and develop plans

to correct them. Management should reward good performance and recognize good examples in order to continuously improve performance.

The last question of the breakout session asked participants to consider other measures of biorisk management performance in the laboratory. Two main points were mentioned. The first was the importance of metrics for measuring performance and thus be able to determine whether efforts were working or not. It was noted that because most measurements of performance were ad hoc, it was difficult to compare the performance of one lab over another and thus one set of measures and approaches for reducing risk versus another. The development of common metrics, although difficult due to the subjective nature of much at work in laboratory biorisk management, was seen as a first step towards understanding the risk situation and improving performance. The second point mentioned was the role a code of conduct for laboratory workers could have in improving performance and regulating behavior. Although not a panacea, it was considered a good addition to traditional, continuous personnel reliability programs.

\section{Session 4 - Training}

The second day moved to a new topic, training, in the afternoon, with a presentation by Dr. Larbi Baassi of the Moroccan Biosafety Association. Dr. Baassi began his talk with a description of the birth of the Moroccan Biosafety Association in October of 2009 after the attendance of a Moroccan delegation from the Ministry of Higher Education to a meeting of the International Federation of Biosafety Associations the previous June. The Moroccan Biosafety Association's mission is to "congregate practitioners of 
biological safety for the promotion of biosafety and to facilitate the sharing of biosafety information." The organization is non-governmental, non-political, and non-profit, and its members seek to cooperate with other individuals or organizations in Morocco and around the world in order to promote biosafety and serve the growing biosafety community within Morocco.

Education and training in biosafety matters is an important means for achieving the Association's objectives. Members of the Association have attended numerous international meetings and workshops since their recent founding, and the Association itself has become affiliated with the African Biosafety Association, the European Biological Safety Association, and the American Biological Safety Association, as well as become a member of the International Federation of Biosafety Associations. Among its activities, it has organized a biosafety workshop in association with the Stockholm International Peace Research Institute and the Swedish Institute for Infectious Disease Control in Marrakech in March of 2010, during which focal points for the Association were identified in the different universities of Morocco. The Association's Biosafety Caravan was developed with an objective to "raise awareness on biosafety and biosecurity through the 14 Moroccan public universities and in one private university" in the country. The Biosafety Caravan includes three conferences given by biosafety professionals and Association members, a set of documents relaying the basics of biosafety and its importance to Morocco, and a stand and table debate on biosafety issues. The Caravan began operating in October and has so far visited several universities in the country. Dr. Baassi then described a convention between the Moroccan Biosafety Association and the Landau Network's Centro Volta facility in the Italian city of Como, signed in Rabat in September, to engage in a joint biosecurity education project. Upcoming activities of the Association include its first annual conference scheduled for May of 2011, as well as a series of regional workshops slated for October and November of 2011 in Tangiers and Rabat on building national capacities in biosafety. Dr. Baassi concluded by thanking Sandia National Laboratories and the US Biosecurity Engagement Program for previous assistance and with a call welcoming audience members to work together with the Association in projects in the future.

The next presentation was given by Giulio Mancini of the Landau Network's Centro Volta in Como, Italy, where he discussed sustainable biosecurity education and dual-use risk issues for life scientists. Mr. Mancini began his presentation with a discussion on the terms "biosecurity" and "dual-use," mentioning these could be used in different ways and in different contexts. According to the definition used in the Biological Weapons Convention Meeting of States Parties in 2008, biosecurity is the "protection, control and accountability measures implemented to prevent the loss, theft, misuse, diversion or intentional release of biological agents and toxins and related resources as well as unauthorized access to, retention or transfer of such material." In his presentation, Mr. Mancini presented a graphic demonstrating how the concepts of public health, biosafety, laboratory biosecurity, and biosecurity in general blended into each other in a form of gradient, and how this made talking about laboratory biosecurity a challenge. Education is one of several important approaches for preventing the theft and misuse of biological agents and toxins. Biosecurity education concerns itself with potential misuses of science and technology, and acknowledges a "role for scientists in being aware that the materials, technologies and knowledge they produce may be misused," and a role "for contributing their expertise to the development and maintenance of preventive policies." 
Mr. Mancini reviewed previous calls for introducing biosecurity issues into mainstream education, and then discussed important issues that must be determined to assess and improve the state of biosecurity education around the world. These included determinations of the number and type of existing initiatives, the sort of person who needs to be educated, the level of education needed, the actual content, and the identification of appropriate experts that could serve as educators. Larger questions included "how to reach convergence between security concerns and the practice of science, freedom of research and science for prevention;" "how to engage the relevant communities (academia, professional associations, industry) on biosecurity education;" and "how to reach sustainability" in biosecurity education programs.

Mr. Mancini proceeded to discuss a series of projects he was involved in to assess attitudes towards biosecurity education around the world as well as to survey the status of biosecurity education in Europe in particular. In general it was found that little was done in terms of biosecurity education in the European continent, though courses in other related areas such as bioethics and biosafety were somewhat more prevalent. Attitudes towards biosecurity generally tended towards indifference, with some interested parties who found practical considerations such as lack of knowledge and time to be limiting factors. However, a particularly interested minority existed that later was to become the starting point for a European Biosecurity Awareness Raising Network, coordinated through Centro Volta. Among the Centro's other efforts has been the promotion of sustainable biosecurity education through workshops in Como and networking with life science faculties through meetings and direct engagement with universities. Furthermore, the Centro has been involved with the University of Bradford in the United Kingdom in the development of an easily accessible international educational module that can be readily incorporated into existing lectures and curricula and which can facilitate the spread of biosecurity information and education. A series of seminars were conducted using the module as a basis but focusing on different aspects such as legal aspects, scientific aspects, ethics, safety, environmental and preparedness, and response issues. Surveys after the seminars found that the audience of mostly biology students became quite interested in the topic and thought awareness of issues discussed should be raised, but that other courses they had been involved with did not do a proper job of this. In terms of sustainability, students showed an interest in a repetition of the seminar series in future academic years, and independent follow ups by faculties and students research groups were organized. Multilanguage modules are in development for 2011 and the European Biosecurity Awareness Raising Network, previously mentioned and coordinated by the Centro Volta, will proceed in developing thematic reports, informative materials, and seminars. Mr. Mancini then briefly touched on other educational resources available on the web as well as other ways in which biosecurity education could be enhanced.

In conclusion, the Centro Volta has learned that little currently exists in terms of biosecurity education and dual use, but that there is interest, and scientists would likely be more interested if they felt they had more "ownership" of this type of education through things like the freely available and modifiable biosecurity module. Ownership of the material by educators could also be enhanced by discussing biosecurity risks in perspective and continuously emphasizing the beneficial purposes of science; by informing scientists on the policy making process; by presenting the growing interest and opportunities 
in prevention, assessment, and communication; and by considering broader contexts and discussions as well as interdisciplinary initiatives. Other lessons learned include the effectiveness of networking and engagement with scientists as a bottoms-up approach, which should be complemented in turn by topdown support, as well as the importance of tailoring to local needs, priorities and interests, developing web platforms that are easy, accessible, complete and updatable, and the benefits of extending the target audience, to medical and nursing facilities, for example. As Mr. Mancini saw it, the way forward included building ownership of biosecurity education, conducting more extensive gap analysis to gauge the situation upon which programs and strategies must be based, developing metrics to measure the effectiveness and impact of existing and new programs and strategies, developing train-the-trainer programs to build capacity in biosecurity education, developing region and country tailored products, integrating security with science and safety teaching, inserting biosecurity in broader "science in society" issues, coordinating top-bottom and bottom-up approaches, and emphasizing the centrality of the Biological Weapons Convention as an international governmental forum which could play a larger role in civil society, could affect outreach to scientists, and could track the state of biosecurity education within States Parties as one of its measurements of progress in biosecurity.

The day's final presentation was given by Dr. Edith Tria of the Philippine Biosafety and Biosecurity Association, on the role these types of organizations can play in training initiatives at the institutional, national, and regional levels. Dr. Tria began her presentation by discussing the spectrum of biological risks and areas in which the WHO and the BWC, as international bodies, have different as well as overlapping interests. Biosafety in the Philippines lags dangerously behind the local expansion of advanced pathogenic research that has been driven by emerging and re-emerging infectious diseases, economic interests, and global security concerns about biological weapons. In order to address biosafety and biosecurity concerns, interest has grown in the biorisk management approach, and there now exists a need to develop policy for an effective and sustainable biorisk management program. A holistic approach to the biorisk spectrum is needed for a structured and prepared government to identify and deal with biological risk. High population growth in the Philippines and an increasing range of risks requires concerted and effective action, including a common risk assessment methodology and common risk prevention activities from region to region.

Dr. Tria proceeded to discuss the history of biosafety and biosecurity initiatives in the Philippines starting from 1990, and the framework within which the country's biorisk efforts operate. The goals of the Philippine National Policy on Biosafety and Biosecurity are "to preserve and safeguard human and animal health as well as the environment against accidental release or malicious use of pathogens," and "to ensure a safe and secure environment by adhering to international standards in the handling, use, storage and transport of pathogens." The scope of this policy includes "all laboratories, government or private, which handle, process, use, store and transport select agents, pathogens and toxins." Organizationally, its board is composed of the Secretaries of various Departments within the government, including a chair and co-chair by the Departments of Health and Agriculture, respectively. Biosafety and biosecurity guidelines for the country have been developed. In addition, a training program for biorisk officers sponsored by the US Department of State's Biosecurity Engagement 
Program has been developed, including a pilot biorisk officer certificate program, to provide best practices training throughout the country.

Dr. Tria then began to discuss the Philippines Biosafety and Biosecurity Association, "a non-profit, multisectoral association dedicated to the enhancement of knowledge and understanding of biosafety and biosecurity issues as preventative measures against bioterrorism." The Association is truly multisectoral, encompassing members from industry, public health, community organizations, government, academia, defense, biosafety associations, international partners, and other relevant organizations. The Association has been involved in implementing a series of advocacy symposia on biosafety and biosecurity with a varied agenda and participants from various areas. Objectives include reviewing the status of biosafety and biosecurity in the country, orienting participants on principles, objectives, and practices of biosafety and biosecurity and its required infrastructure, identifying gaps and drafting follow-up actions for strengthening biosafety and biosecurity practices in the Philippines, and building partnerships among multi-sectoral stakeholders locally and internationally. Indeed, one of the Association's visions is to strengthen the national biosafety program through international linkages. The Association provides a platform for raising awareness, building capacity, channeling partnerships and collaborations, and fostering networking between members themselves as well as with international partners.

\section{Breakout Session 4 - Training}

\section{Summary}

Breakout sessions focused on two aspects of training as related to biorisk management in laboratories: appropriate content and material, and the role of different means and methods to conduct training. Discussions included the extent to which different approaches for training biosafety and biosecurity were required, when training should commence in a student and lab-worker's education, administrative issues of implementation, the role of outside expertise and biosafety associations, and the use of technology in different teaching contexts.

\section{Breakout Session 4a - Content in Training}

The first topic discussed in this breakout session regarded whether biosafety and biosecurity should be regarded as separate concepts during training. The general consensus of participants was negative, there should be no separation. Biosecurity and biosafety were regarded as being intrinsically linked. Because biosafety programs tended to be older and more established, it was suggested that biosecurity be "added" to existing biosafety training programs. It was also noted that because of unfamiliarity with the concept, there was often resistance in previously open bioscience laboratories towards the idea of biosecurity. How biosecurity measures were implemented and communicated was seen to be very important. Framing biosecurity as "good for safety, good for science, and good for new opportunities" was seen as important. Another way to frame biosecurity, as well as dual-use, was as ethical issues. Having the term biosecurity separate from biosafety was not seen to help anyone. An important point brought up was the fact that most biosecurity measures were already generally taken for biosafety reasons, so the implementation of biosecurity was not in fact so difficult. There are some areas of 
conflict between biosafety and biosecurity, and the best approach for reconciling those conflicts was seen to be open discussion. Because topics of safety and security are so broad, it was mentioned that biorisk was becoming less an area of training and more of an academic field of study. This led to ideas on teaching aspects of biorisk early, during undergraduate education, and perhaps even earlier, to begin introducing students to the concept as soon as possible and thus more effectively move towards a riskconscious culture.

The next topic of the breakout session considered whether training should focus on practical skills or theoretical concepts. Generally, it was seen that biosafety tended towards a more practical sort of training, whereas biosecurity was more conceptual. Biosafety training in large part was seen as being part of training in good science and good laboratory practices. As such, biosafety training became part of general scientific training and a related to the general competencies of the workforce. Content in biorisk training, whether practical or theoretical, tended to depend also on the particular agents and activities of the laboratory, as well as the other measures chosen to mitigate some of the associated risks. Therefore, basic safety and good laboratory practices training may be sufficient for basic laboratories, but training should be very different in laboratories working with highly pathogenic organisms under containment. Practical training is more important and more involved in complex laboratories, and some level of theory on the workings of engineering systems, personal protective equipment, and microorganism pathogenicity, for example, becomes necessary for workers to understand their risks and successfully adapt in the event of an emergency, or even during day to day work. Whether practicality or theory is emphasized depends as well on the desired outcome of the training, which must be clearly established prior to training design. Bloom's Taxonomy of Cognitive Domains was identified as a powerful guide in developing trainings, one that helped identify methods based on human psychology appropriate for particular learning goals and objectives. It was noted that different personnel had different knowledge levels as well as different requirements for knowledge, based on their expertise as well as their responsibilities. Novices had a greater need for concrete information, the so-called "what to do," whereas experts have a greater need to know the reasons behind certain plans and actions, the "why to do it." Those in a transitional phase between novice and expert would need to know "how to do it."

The next guiding question of the breakout session dealt with the role of management in deciding the content of training. This role for management was seen to depend on the context: the type of the lab and the regulatory environment it operated in. It was thought that content in general should be determined by a technical expert, either a qualified biosafety office or scientific management. Top management's responsibility was to endorse and training content and support it with resources, including time. Top management's responsibilities included determining the acceptability of risk and making decisions based on cost-benefit analysis. It was observed that when management is more directly involved in training, they seem to be more interested in maintaining and funding the programs. It was asked whether certain aspects of training needed to be mandated by law, in particular, biosecurity training. What incentives exist to train more broadly, encompassing things like biosecurity, if content in training was left entirely up to institutions? In biosafety, legislated content in training was seen as plausible given the existence of a common core of knowledge to which it is necessary for all to 
be exposed. Elaboration on that core and customization based on particular laboratory conditions could occur on top of legislated requirements. Whether or not this was desirable, it was seen, depended on different national, regional, or local realities.

The final question on content dealt on whether and how the content of training should change over time. General consensus was quickly reached on the necessity for content to change over time; however, it was recognized that key elements of content would naturally remain constant. Proficiency in training must evolve and continually improve. Different training methods and learning levels were seen to be required for novices versus experts, which would require different content. Content must also change based on evolving technical progress and knowledge. Content must always be linked to lessons learned after incidents in a laboratory in order to ensure positive and continual improvement. Content must also change in response to gap analyses done on the appropriateness of existing programs. Training content must be based on cost-benefit analyses as well as worker retention: it must be determined whether the value of a particular training configuration was worth the time for preparation, delivery, and ongoing evaluation based on existing resources and needs. Other general points mentioned included the importance of starting biorisk education early in a student's career, as well as the importance of establishing biorisk as a desirable profession and thus increasing the credibility of programs and trainers. It was also noted that biorisk training was a very interdisciplinary field, and this created difficulties in terms of deciding who was an expert and how one creates experts. Experts at some level must have knowledge of science, engineering, psychology, law, security, ethics, and other fields. The diversity of content increases the difficulty of working in the biorisk field as well as engaging in and developing training programs.

\section{Breakout Session $4 b$ - Methods of Training}

The second breakout session on training focused on methods and tools most appropriate for biorisk teaching and preparation. The first guiding question asked the role of outside and international trainers in institutional training programs, and to what extent training expertise should be fomented in-house or contracted out. The first thought expressed was that there should be some level of in-house expertise or at least responsibility for training, in the form of at least one full-time person with responsibility over training. It was discussed that training "should be conducted by the most appropriate people necessary to perform the training in a manner that is most relevant to the facility," whether or not those people were necessarily in-house employees. One advantage of in-house trainers was familiarity with the institution, thus tending towards an easier assessment of needs. Issues of language were also raised; outside experts may not be able to communicate as effectively as a local expert if language is a barrier. Depending on the level of biorisk expertise in a country, policy might direct basic training aimed at a wider audience be conducted by local experts, and more unique, technical expertise for advanced topics could be drawn from the global community of experts. Online relationships between institutions and associations around the world could serve to aggregate knowledge and expertise, mentor, and foster collaborative actions between experts for training. Training courses could be updated using outside expertise. Depending on the context, the use of outside experts could enhance the credibility of a training program and lend weight to the importance of the topic. The concept of training trainers was brought up, and it was mentioned that this sort of program would be most effective through the 
identification of the right two or three people, since not everyone has the skill and natural ability to train and instruct others.

The next question asked was how one decided on and what factors were involved in choosing the audience and frequency of biorisk training. It was thought by participants that at some level, everyone who at some point enters a laboratory should be trained, including cleaning and engineering crews. It was also felt that there was a broader audience that needed exposure to the needs and functioning of laboratories, including persons on the boundaries of the institution, for the sake of general awareness, in particular in the event of an incident or emergency. It was thought that, in line with previously expressed thinking, the audience for training should depend on the institution's particular circumstances, and so broad prescriptive policies were likely to be inefficient. There was varying opinion on the idea of a case-by-case individualized training plan model, with some preferring some segmentation of training plans but abhorring higher costs associated with an individual focus for everyone. The use of audit and inspection findings in selecting audiences for particular training was thought to be extremely important.

Workforce development plans were discussed as a way of strategically adjusting employee training to aggregate laboratory needs. It was noted, however, that it was rather challenging to ensure that the right people were channeled into the particular trainings. In terms of the frequency of training, it was noted that as a default, training often was better than not, to ensure that needs were met. Adjusting frequencies to needs was seen as challenging. The issue of competency versus training was brought up, emphasizing the difference between the two. Training was "easy" in that one could check off a person's name as having attended a course and having completed certain training. But whether the "trained" person is in fact competent is another story. It was understood that frequency was dependent on the tasks in the laboratory and the particular individuals working on those tasks, and as such was something that was likely to be fluid requiring continuous adjustment. Factors seen to be important affecting the audience and the frequency of training included employee rotation and turnover rates, how frequently standard operating procedures were updated and changed, what sort of research was going on in the laboratory, the method of training and costs, how frequently incidents occurred, time spent away from a particular sort of work, and training budget limitations. One important issue for training programs to consider in choosing content, methods, frequency, and audience in training was, in fact, overtraining, or training persons on topics and skills they already know. For example, there is no need to teach an electrician how to change a light bulb. This could be an important cause of wasted resources. Another issue was simplification of signage as well as procedures in a laboratory, which would, among several other benefits, potentially lead to lower training costs.

The next question addressed dealt with the role of computers and online technology in training. It was generally thought that information technology should play a supportive, not exclusive, role. It should act as a mentoring tool for theoretical, not practical, training. Concerns were expressed over a reliance on Internet-based training, in particular for countries where online access was expensive or difficult. Computerized tools that could be adapted as both online resources and as portable media, such as compact discs, could increase the reach of those materials. It was noted that technology adds value for sharing and access to certain kinds of information, but was not effective for sustainable learning. Under 
limited circumstances, however, with limited budgets or other restrictions, it was seen as being definitely better than nothing. One advantage of computerized tools over traditional group training was the fact that a user could proceed at their own pace. Another teaching method, video training combined with group discussion, was also mentioned.

The last question and topic discussed dealt with the effective maintenance of training programs. Items mentioned included the need for trainers as well as those trained to stay within organizations; that is, for organizations to find ways to combat the "brain drain" phenomenon. The use of computers and online training as support was seen as a useful tool for maintaining the viability of programs, as well as collaborations and exchange between institutions in order to introduce new ideas and share best practices. Biosafety associations were also seen as useful in this role. The support of senior management was seen as key. A previously mentioned idea - a responsible, dedicated person whose sole responsibility is training - would likely be a positive force in any institutional training program. It was seen as difficult to determine the best strategy for identifying international sponsor support for training. The development of a survey to better glean what works and what doesn't was seen as a useful step forward in this regard. Coordination between international sponsors for more effective support and coverage of needs was also seen as important. An effective application screening and selection process to choose candidates for training most suitable to the program and to needs was seen as being more effective and, in the end, less costly than blanket screening. Setting terms and conditions for trainees, not just checking a box but requiring demonstrable progress, was also seen as a way of proving the effectiveness of a particular training program and so justifying its maintenance to responsible personnel. 


\section{Day 3}

As in the second day, the third began with summaries of the previous day's breakout session discussions by session rapporteurs. The morning's focus then shifted to presentations on "National Oversight and Regulations" as related to biorisk management, and later a final rapporteur report and wrap-up of the workshop.

\section{Session 5 - National Oversight and Regulations}

The final topic area of the workshop focused on "National Oversight and Regulations" for biorisk management and commenced on the morning of the third day with a presentation by Dr. Sanders Banus of the National Institute for Public Health and the Environment (RIVM) of the Netherlands. Dr. Banus discussed his country's efforts at managing laboratory risk and large-scale incident response. He began his presentation by describing RIVM as a "leading center of expertise in the fields of health, nutrition and environmental protection." RIVM's mission is "to benefit people, society and the environment, matching its expertise, knowledge and research with that of colleagues around the world." It achieves its mission through research, policy support, national coordination, intervention, and communication. Within the RIVM, the Center for Infectious Disease Control Netherlands is tasked with detecting, controlling and preventing infectious disease for the benefit of public health. It achieves these ends through its diagnostic service, surveillance of disease, and through the conduct of scientific research. It also coordinates infectious disease control as well as responses to outbreaks, and advises the central government, the health establishment, and the general public on infectious disease issues.

The Environmental Incident Service, also within the RIVM, is a group of experts from several different departments within RIVM that can be called upon at any moment to serve with their expertise in the event of an emergency in the Netherlands. They can be called in to assist local, regional, or national authorities to limit the effects of an attack, accident, or other sort of incident, and do so by generating, collecting, integrating, and interpreting scientific data and converting that data into information that can be used directly by authorities. The Service is prepared to take samples and perform measurements on site, model the dispersion of harmful substances, and provide advice on minimizing risk for people and their surroundings. Dr. Banus proceeded to discuss some of the different threats the Environmental Incident Service has been and could be called upon to respond to, including anthrax attacks through the mail system; dispersal of pathogens in the food supply; and attacks using biological, radiological, or chemical substances on individuals, among others.

The Dutch government responds to CBRNE threats in a multi-layered and multi-disciplinary manner, depending on first degree responders such as police and fire brigades to alert second degree responders, such as RIVM and the Netherlands Forensic Institute, as needed. These secondary responders can, in turn, alert other networks of experts as required. These expert networks, along with the first degree responders, can also directly alert the Dutch military in the event it becomes necessary. The Netherlands also relies on a national network of laboratories that can be activated in the event of a terrorist or CBRN incident and combines the capacities, knowledge, and expertise of various personnel and institutions. The mission of the network is to provide authorities with quick and accurate analytical 
data to support efficient action. A mobile laboratory is available for use at a moment's notice as the front office of this network in the event of an incident.

Dr. Banus then described the state of biosecurity in the Netherlands, turning to the 2008 European Union definition of "laboratory biosecurity" as "the physical and administrative measures that secure biological material and information that could cause harm to health or economic loss as a result of malicious release, intentional loss, theft, or misappropriation." In 2006, the Netherlands held a review to determine the locations of the country's CBRN materials. The biological component of this review quickly became outdated as a result of the complexity and dynamism of the biological field, and it soon became clear that there was a need for a coordinated biosecurity regime to handle biological security at the national level. Intrinsically, biosecurity issues exist in a variety of areas corresponding to diverse government bodies: occupational health issues with human pathogens, environmental health issues with genetically modified organisms, plant and animal health issues, public health in terms of outbreak management, response services, requirements due to the EU CBRN action plan, and Biological Weapons Convention obligations.

The Coordinated Biosecurity Regime project was developed in order to handle these various elements and began being implemented across the Netherlands in January of 2010. The project has an expected completion date of June 2011. The Regime will incorporate an updated review of biological locations in the country, a review of the legal framework under which biosecurity issues are handled, and will perform an inventory of policy options among the different ministries involved. It will sport an umbrella-like structure and suggest ways of organizing and supervising biosecurity-related endeavors, anchor biosecurity into organizations, and develop ways of disclosing critical information to first responders. The goal of its approach is to be pragmatic by connecting existing projects and processes, employing learning-by-doing methods and best practices from surrounding countries, all the while maintaining international links to the EU CBRN process as well as developments in the Biological Weapons Convention. In addition, the Regime involves the development of a toolkit to help institutions improve their level of biosecurity. The toolkit addresses seven elements: awareness, personnel reliability, transport security, information security, material accountability, incident response and physical protection, and allows institutions to easily self check their current security status, identify gaps to be filled, and help fill them through suggested best practices. The Dutch Coordinated Biosecurity Regime will combine what Dr. Banus considered were the best of three different approaches: selfregulation through the tool-kit and implementation of best practices, a combination of safety and security considerations, and directive action through the development of a regulatory framework and through toolkit-based inspections and supervision.

The next presentation of the day, given by Dr. Won-Jong Jang of Konkuk University in Seoul, regarded the Republic of Korea's efforts to regulate biological risks within its borders. Dr. Won-Jong began his talk with an introduction to the implementation of biosafety and biosecurity as it had occurred at this point in South Korea. He described the process as evolutionary, from a global concept of dangers in the laboratory to a more formal consideration of biosafety, the further addition of biosecurity to the thought process, and the final maturing of the concept into biorisk management. Furthermore, he related the parallel development of government involvement in these topics evolving into an expansion 
of interest outside the government to civil society through the Korean Biosafety Association, as well as personnel in institutions around the country. As time has passed, implementation of biosafety has increased as has an awareness of the issues.

Politically, the Republic of Korea signed the Biological Weapons Convention in 1972 and ratified it in 1987, joined the Australia Group in 1996, and signed the Cartagena Protocol on Biosafety in 2000. Several ministries and their agencies in the Korean Government are involved with biosafety and biosecurity issues. In particular, the Korean Centers for Disease Control (KCDC) under the Ministry of Health, Welfare, and Family, has a Division of Biosafety Evaluation and Control established in 2005 which plays an important role associated with Biological Weapons Convention legislation. This Division within the KCDC is charged with national certification of BSL3 and BSL4 facilities, the management of high risk pathogens within Korea (that is, regulating the movement, possession, waste handling, and other issues related to these pathogens), approving certain experiments on Living Modified Organisms, conducting education and training, and publishing documents such as national guidelines, the national biosafety manual, material safety data sheets for declared high-risk pathogens, and others. Several key legislations and regulations cover biorisk management in Korea. These include the Bioscience Technology Promotion Act regulating recombinant DNA molecules, the Prevention of Contagious Disease Act which controls highly dangerous pathogens, an Act on Waste Management that controls activities related to waste handling, an Act on Transboundary Movement of Living Modified Organisms, an Act on the Prohibition of Biological or Chemical Weapons related to international obligations under the Biological Weapons Convention, a Plant Quarantine Act controlling the import and export of plant pests and pathogens, and an Act on the Prevention of Contagious Animal Disease that similarly adds controls to the import and export of infectious animal diseases. Imports and exports in particular are regulated through the Ministry for the Knowledge Economy and the KCDC, who jointly decide whether an institution is given permission to import organisms and approve plans for the transfer and possession of organisms. This process of transfer and possession is regulated in turn directly by the KCDC, in accordance to guidelines published by it and based on the World Health Organization's guidance for pathogen transport.

Another area in which the Korean government regulates laboratories is through biosafety level certification based on the US Biosafety in Microbiological and Biomedical Laboratories manual, commonly known as the BMBL. Biosafety Levels 1 and 2 are regulated by the Ministry for the Knowledge Economy and require only registration with the Ministry, whereas Biosafety Levels 3 and 4 require certification performed by the KCDC. Korea established in 2006 risk groups for microorganisms, resulting in 32 pathogens falling under KCDC regulation. There exists in Korea a nation-wide approval process for research into Living Modified Organisms, which depends on the type of research being conducted. The National Guideline for Laboratory Biosafety, enacted in a revision of the Prevention of Contagious Disease Act, establishes Institutional Biosafety Committees and describes their responsibilities, organization, and the role of the Institutional Biological Safety Officer. Civil developments in biosafety and biosecurity include administrative, financial, and technical support to civil entities provided by the KCDC, as well as the establishment of the Korean Biological Safety Association in November of 2008. The latter's function and role is to improve the biosafety environment 
in Korea by providing biorisk education and training, assistance in managing certified high containment facilities, assistance in developing and communicating new techniques for biosafety and biosecurity, making policy suggestions to the government, and introducing a licensing system for Biological Safety Officers. The Korean Biological Safety Association operates in partnership with the KCDC as well as other international biosafety associations such as those of the United States, Europe, Asia-Pacific, Japan, and others.

In conclusion, Dr. Won-Jong provided perspectives for the present and near future in Korea, discussing the translation of the CWA 15793 document into Korean, completed by the KCDC in July of 2010, as well as upcoming revisions of the Prevention of Contagious Disease Act to update the dangerous pathogen list, further develop national certification for Level 3 and 4 laboratories, establish requirements for work with high risk pathogens, and reassign several ministerial responsibilities. An update of the living modified organism legislation is also under consideration to simplify practices. Finally, Dr. Won-Jong noted the Korean government sought to improve biorisk management through partnership with civil institutions to expand biosafety and biosecurity culture, implement a biorisk management pilot program, revise legislation and regulation, and introduce a Biological Safety Officer certificate program through the Korean Biosafety Association and the KCDC. Stronger international cooperation in biorisk management was seen as an important present and future goal.

The final presentation of the day and the workshop was conducted by Dr. Anwar Nasim of Pakistan, who discussed his country's national biorisk regulations and international engagement. Dr. Nasim began by discussing his background and experience, which has been quite varied and has contributed to his unique perspectives in the field. Dr. Nasim has experience with radiation and its effects on biological systems, and suggested aspects of the assessment and management of risk in the radiological field could be adapted and utilized in the field of biosafety and biosecurity. Dr. Nasim then continued with a description of Pakistan that revealed contrasts, such as the fact it contains several major biotechnology centers and 124 universities, concurrent with widespread poverty, low literacy rates, and an economic dependence on agriculture.

Pakistan has been active in a variety of international biosafety and biosecurity initiatives, with Pakistanis attending conferences around the world and meetings having been held in Pakistan with international partners in order to promote biorisk management. National efforts in the field include passage of the Biological and Toxin Weapons Convention Implementation Act of 2010, guidelines for the development of a code of conduct for life scientists developed in 2010, and national biosafety guidelines developed in 2005. An education and networking project on dual-use issues and biosecurity for university students in Pakistan has been developed in association with Giulio Mancini of the Centro Volta in Italy and James Revill of the University of Bradford in the United Kingdom.

Pakistan has been committed to the Biological Weapons Convention, and seeks to support it through existing national mechanisms of disease surveillance, mitigation and response, through collaborative arrangements with other governments and international organizations, and through its own capacity in terms of expertise and training which could be offered as assistance. Dr. Nasim continued with an explanation of his concept of NGls or Non Governmental Individuals, in essence highlighting persons 
who strive for the betterment of society. Dr. Nasim and two others authored a book on the role of champions in facing global challenges, stressing that highly motivated and dedicated individuals are essential for effecting change, and this applied to the field of biorisk management.

\section{Breakout Session 5 - National Oversight and Regulations}

\section{Summary}

Breakout sessions focused on optional versus mandatory government regulation in an attempt to discern the bounds and obligations of state authority in laboratory biorisk management. Areas discussed during these breakout sessions included the government's duty to set biorisk system objectives and obligations, promote awareness and education in biorisk issues, and provide variable levels of funding depending on situations. Oversight of systems, inspection and verification of performance, and a blending of government performance-based as well as prescriptive regulation, among other issues, were also discussed.

\section{Breakout Session 5a-Optional Considerations}

In this breakout session, participants began by discussing the sorts of risk management policies they felt should be developed by institutions rather than government and international bodies. Institutional risk management policies included the determination and development of core competencies among the workforce as well as actual policies for controlling quality. It was seen as the duty of the government to set objectives and certain basic obligations, but that it was the decision of institutions to determine specific means or to follow international guidelines. The role of government was seen to be a reflection of culture; some cultures will demand state regulations be more prescriptive while others would prefer more institutional freedom.

The next topic of discussion involved institutional adherence and compliance to international performance-based standards like the CWA 15793 and whether this should be voluntary or directed from government regulations. In general, participants felt adoption of the standard should be voluntary, but the government could incentivize adoption through funding. Voluntary adoption would allow institutions to pick and choose elements of the Standard that suit them best, as it was seen that not all laboratories, particularly smaller ones, could adopt the Standard in full. Voluntary adoption could improve "buy-in" by increasing "ownership" of the Standard and its provisions by institutional management, since only those interested and those seeing the value of adoption would be implementing it. Conversely, voluntary adoption could reduce the speed with which some of the benefits of the Standard could be extended across a country. This, however, could be modulated through incentive mechanisms such as conditional funding.

The following topic of discussion was concerned with the benefits and limits of a "best practices" approach to defining risk management strategies. Some advantages of a "best practices" approach included a shorter review cycle, harmonization of standard operating procedures across institution, easy adoption, and general availability. Disadvantages included the partial reduction in the thought processes required for the creation of one's own practices, thus resulting in a reduction in capacity by 
the adopting institution. One point noted was that an institution can't rely on best practices to define a risk management strategy until best practices themselves are defined. Best practices allow a laboratory or institution to achieve a certain capability, and what that capability and what those criteria are must be defined. Best practices, it was noted, should be universal and performance-based, as well as "resource appropriate."

The role of voluntary biosafety and biosecurity association in laboratory biorisk management was discussed as the next general topic. It was noted that biosafety and biosecurity associations could help raise awareness of biorisk issues and provide education and training as well as mentoring, and thus help build national workforce capabilities. The organization of biosafety and biosecurity experts within an association could allow for the sharing of good ideas and assistance to national governments in developing regulations, could provide consultations and render expertise to institutions, could serve as a communications route between institutions and policy makers and, if sufficiently large, could even be a possible source of funding for institutions.

The final topic discussed in the breakout session was the issue of whether there were certain, minimal requirements governments needed to mandate in order for a best practices environment to flourish. Participants generally regarded the answer to this as yes. Government has a role in creating categories of action and mandating those actions be taken. However, prescription of what or how was unnecessary. Assuming defined best practices, participants noted that government should set guidelines or goals. It would then be up to institutions to implement specific, resource-appropriate plans on how each goal would be reached safely and securely. Government could reward good behavior and punish unacceptable results by tying funding to performance.

\section{Breakout Session 5 b - Government Requirements}

The first topic of this breakout session involved the responsibilities of government in regulating risk in institutions. First and foremost, it was seen that a primordial responsibility of government was to protect the nation, however that may be necessary. Therefore governments must take stock of the biosafety and biosecurity risks posed by laboratories, weigh them against the many benefits of these institutions and other constraints that may exist, and decide on proper courses of action. Those courses of action could vary greatly depending on the government, culture, and situation. Government action can occur in a number of ways. Governments provide legal frameworks for laboratory operations and, through funding and permitting or through direct regulation, hold the power to influence or determine the nature of a country's laboratory operations and infrastructure. Governments have a responsibility of oversight over laboratories in their jurisdiction, and can structure national mechanisms for inspection and certification. Oftentimes, government can also be the agent carrying those inspections and certifications out. At a minimum, governments can register laboratories to better track and understand the state of the country's bioscience industry for safety, security, scientific, and economic reasons. Also, through the national education system as well as through national institutions and regulation, government can be involved in the training and preparation of laboratory personnel and otherwise influence biosecurity and biosafety education. Experts within the government can assist laboratories and institutions by providing technical advice on safety and security. Through a variety of mechanisms, government could play a role in strengthening the private sector's support for biorisk management. As 
an overarching authority, government could formulate national strategies to integrate diverse partners in an effort to better mitigate risk. Government would have to implement international treaty obligations at the national level, including multilateral treaties such as the Biological Weapons Convention that deal with aspects of biosecurity. And finally, the government has a role to play in promoting regional, national, and international coordination and cooperation on biorisk topics.

The next topic of the session involved discussion on the role governments should play in regulating work with particular agents and toxins in order to mitigate risk. The general consensus among participants was that it depended on a variety of factors. Generally, it was agreed that there was a level of dangerous activity beyond which the government had a responsibility to intervene. However, there was also wariness on relying solely on lists of agents. Risk groups don't capture nearly everything; there are different strains of agents and different activities that could be performed at different scales. There are also issues of risky knowledge and risky technology, and biological components such as virulence factors or segments of DNA that would not necessarily be captured by risk groups. Risks also depend on the country. For example, work with Foot and Mouth Disease Virus is not as risky in an endemic country as it is in a non-endemic one. As a result, risk groups and list of pathogens are at best incomplete. It was noted that in many countries, the most effective method of regulating agents given political and systemic constraints was by regulating transport or import policy and not by regulating agents directly. There was general agreement that if there were to be agent lists and agent-based regulation, it should be country-specific and not an international sort of regulation. Regulation of agents could in some circumstances best be delegated to the institutional level. The process of developing policies for the regulation of agents was seen as related to a country's Biological Weapons Convention obligations, despite the fact the Convention does not specify which particular agents are of international concern. Generally, a global understanding of dangerous and not-dangerous agents, combined with a local or national direction, was seen as a positive although incomplete step forward.

The next topic under consideration regarded how government oversight could best operate to ensure laboratories and institutions complied with regulations. Consistency in audits and inspections, documents reviews, and accident and incident reviews was seen by participants as being a very important element in compliance with regulations. Institutions felt the regulatory processes need to make sense. A better appreciation by the regulator of the impact of oversight and achieving a balance over productivity and oversight was also seen as important. Extending the notion of networks and collaboration to institutions dealing with regulation, one thought regarded connections between responsible persons in regulated entities to be potentially useful for sharing data and experiences. The development and use of standardized toolkits for different sectors was also suggested as a means of simplifying compliance. The importance of knowledgeable oversight was also expounded, as well as the advantages of proactive versus reactive support. The frequency of inspections, it was thought, should depend on a scientifically assessed level of risk. And finally, support for growth in the culture of biorisk management was seen as an important means towards improving systemic as well as programmatic compliance with regulations, as an awareness of risks and the process of considering how best to manage them would increase conscientiousness on the importance of safety and security regulations and, by extension, on compliance. 
Next, participants were asked to consider the extent to which performance-based risk management approaches could effectively form part of government regulation. The general consensus was that this was possible, but that there would be difficulties translating performance-based risk management to an inspection process, as there would be a greater need to interpret situations rather than check boxes off on a list. It would thus involve re-training inspectors as well as personnel in regulated entities. One approach could be through the use of non-mandatory examples of solutions in the spirit of bestpractices. It was noted, however, that in many instances there needed to be a combination of performance-based and prescriptive approaches to government regulation, as relying solely on one approach did not appear to participants as being optimal. The process of reconciling and merging the two approaches would likely be challenging and was not addressed.

The final topic considered was that of minimal requirements for effective biorisk management that fell exclusively under government jurisdiction. Participants considered there to be country-specific sets of minimum requirements; that is, the level of "minimal" depended on the country. The mix of requirements was expressed through regulation and legislation, soft or hard oversight, and types of registration and certification. At a minimum, government must be effective in its regulatory responsibilities at whatever level it chooses to regulate. At a certain point, government's exclusive responsibilities ends and communities, contractors, and others influence the mechanics of implementing biorisk management solutions. Determining the limits of government's intrinsic responsibilities was difficult and ultimately depends on its responsibilities to safeguard public health and security, as well as its effectiveness in doing so. The discussion turned to the responsibility of government to support oversight with funding in order to ensure a high quality oversight process. Government officials and regulators that do not understand biorisk issues and cannot perform effective reviews and inspections of laboratories represent a failure of government oversight. After all, effective oversight through trained inspectors is how governments exert control in order to fulfill their responsibility to protect the nation's security and public health.

\section{Session 6 -Wrap-up}

The final session sought to bring together all topics discussed during the three-day workshop and attempted to call out the most important areas future attentions should be focused on, in particular in the context of the upcoming Biological Weapons Convention review conference. As presented by Jennifer Bae of the US Department of State on the first day of the conference, organizers sought the advice of the convened scientific and technical community on how to shape policy to better meet the needs of the laboratory.

Areas discussed during this final session included the need for more clarity and cohesion of government and international requirements for biorisk management, including addressing of issues concerning the implementation of international performance-based standards, the establishment of common criteria for compliance, and cross-border harmonization of oversight standards and requirements. It was seen there was a need for dissemination of information on training and outreach programs as well as further promotion of interaction between biorisk communities in different regions of the globe, and the BWC's 
Article $\mathrm{X}$ mandate to promote peaceful life science cooperation was seen as a previously underutilized potential mechanism for this sort of activity. A country's awareness level as to issues of biorisk management was seen as a possible variable to track and report to BWC conferences as a metric for the success of biorisk engagement and dissemination efforts. Other suggestions included tracking, given proper mechanisms, of the effects of genetic research and change on pathogens that could result in altered virulence affecting laboratory biosafety, biosecurity, and public health. International workshops such as the one congregated were certainly seen as useful vehicles for moving discussion and influencing international perspectives on laboratory biorisk.

\section{Major Themes and Next Steps}

\section{Major Themes}

Throughout the workshop, five major themes continued to take prominence. These themes regarded Networks and Partnerships, Expertise and Human Capacity, Sustainability, Oversight, and Implementation. Throughout the presentations and breakout session, regardless of the topic, these five themes played a role in how the issues at hand were discussed and each serves as a lens in which to view the discussions.

The development of Networks and Partnerships will be critical in the development of biorisk management systems. These need to be built up to allow for sharing of information and best practices and to look into cultural understandings. Participants put forth that workshops such as this can be a forum for such discussions because of its international focus. A challenge that needs to be addressed regarding international partnerships and networks is that there are very distinct cultural differences that cannot be ignored. They must be addressed and bridges formed to strengthen the ties and communication throughout the international community. Further, networks and partnerships are not only necessary internationally but also domestically. There needs to be stronger communication to national organizations to help maximize collaboration within the region. By doing this, overlap can be avoided where possible which can minimize the use of resources.

To build networks and partnerships, the second theme becomes critical, Expertise and Human Capacity. Without the expertise and human capacity within a country, it is impossible to form meaningful, mutually beneficial partnerships. This theme covered several topics. There was recognition of the presence of an existing talent pool of experts in biorisk management. However, there continues to be a need for a greater number of quality workers who are capable and trustworthy to enter the field. A shift in focus from a technological basis to a human capacity basis needs to occur to allow for the greatest dividends on resources spent. This focus on human capacity will help to develop a broader and deeper understanding of biorisk management principles across all stakeholders. While doing this though, training must be appropriately targeted to the right stakeholders and be tailored to provide the appropriate information for that group. 
The two themes both act to support the Sustainability of Biorisk Management. Having the experts and professional networks will help to create a strong base for this system and allow for the support of institutions that are just beginning to engage in biorisk management. One thing that was made clear was that there must be an understanding that it is constantly evolving. This makes it difficult because whether an institution and its managers are well seasoned in biorisk management or just starting out, they still need to maintain the commitment to keep diligent and forward looking in the approach to maintaining and sustaining biorisk management. To keep forward looking, biorisk management needs to have mechanisms in place to stay updated and abreast of new practices and principles occurring throughout the community. The community needs to stay focused internationally and not look to a subgroup of specific "model" institutions due to the variability of biorisk management and the potential inappropriateness of certain techniques depending on the individual laboratory's situation.

From an Oversight perspective, there needs to be a commitment from the international community, national community, and institutional base to conduct oversight of biorisk management. There is a global interest in seeing a standard, such as CWA 15793, implemented as a biorisk management system. The international community and national governments must provide leadership, commit to, and fund sustainable biorisk management systems. With that understanding, regulators need to understand the role of regulators and not take on the role of the regulated community and vice versa. This is to ensure effective use of resources, knowledge, and expertise. To further ensure an effective use of knowledge national governments need to promote a national institute of biosafety to help to house the expertise of the nation's biosafety community.

The final major theme that overarches all of the aforementioned themes is that of the need for Biorisk Management System Implementation. As has been made clear, biorisk management has many facets and layers to it and because of that must be a flexible, country based, and risk based process. Further it must not sit solely within biosafety or biosecurity but help to bridge the two to bring them forward in the minds of institutional and governmental overseers. By creating a country-based tool, biorisk management can be adapted to each country's specific situation, allowing for variability between countries. On a smaller scale, for each laboratory there is no "one size fits all" solution that can be taken off of the shelf and implemented directly. Documents like CWA 15793 are not meant to be implemented as is but used as a tool to develop the necessary and appropriate management system. To further implement a biorisk management system, networks and partnerships must be utilized to allow for the sharing of best practices to help with the continual improvement of the field. Finally, in implementation, it is critical to recognize that there is no such thing as zero risk. Biorisk management is within a system that must have some acceptable risk and therefore implementing within this environment requires the careful consideration as to what is an acceptable level of risk given the biosafety and biosecurity concerns of the specific laboratory. 


\section{Next Steps}

During the Department of State's opening remarks, a request was made for "advice and thoughts on how we can shape policy to better meet the needs at the laboratory level." In the final session of the meeting this request came full circle, and participants were asked to suggest specific next steps in biorisk management. Consensus was not attempted in determining these next steps and they are solely the view of the individual participants who proposed them.

First, because of the completion of the three-year approval cycle in February 2011, one immediate concern was the renewal of the CWA 15793 document. Further recommendations for the codification of CWA 15793 as a national standard were discussed, though there was pushback as to the necessity and possible ramifications of having the CWA 15793 codified. In the light of discussions on verification measure for the BWC, suggestions were made that monitoring and reporting to the BWC of awareness levels of biorisk management and other biorisk issues at the national level could serve as a possible surrogate. The use of the CWA 15793 could serve as a platform for developing unified oversight standards and spark national dialog on items needing to be included in such oversight standards. These discussions can further be used on the international level to highlight the existence of inherent differences between countries and that country-to-country variation must be accepted as a fundamental element of international biorisk management. Additional questions on the international scale revolved around the need to determine the appropriate international body to coordinate conversations and disseminate outcomes. The need for determining roles, responsibilities, and accountability of international organizations, such as WHO, OIE, and FOA, was also deemed necessary. A possibility for advancing biorisk management internationally was through the development of a program modeled after the Doctors Without Borders program that would allow for the circulation of expertise around the world in the area of biorisk management.

Suggestions regarding training also came up, stressing the need for change in the way biorisks are mitigated. There was a general sense of a need to adjust mitigation efforts from a traditional emphasis on upgrading facilities and technology towards an expansion of human capacity and expertise. Such a change could allow for greater returns on investment in biorisk management, saving time and resources. Training needs may further be met by the dissemination of information through outreach programs and national biorisk associations. Final suggestions made revolved around the continued good practice of science and engaging new and emerging fields. These revolved around biorisk management's role in pathogen security as well as in ensuring emerging scientific trends like biological art and Do It Yourself (DIY) biology develop in a safe and secure manner. By showing the benefits of biorisk management and gaining the sort of international support discussed earlier, it would be possible to meet final goals of finding ways to control, manage, and allocate funding for biorisk management in the future. 


\section{Recommendations to the Biological Weapons Convention}

Dr. Octem's welcoming remarks on the first day of this workshop served as an appropriate introduction to the challenges of mitigating biological risk in the modern age. In many countries around the world, biotechnology industries have been growing and life science research has been progressing each at an unprecedented pace, presenting new challenges in multiple areas that are often difficult to understand and properly address. Biological risks are one of these challenges. Countries facing such challenges are often tempted to exert control through legislation empowering ministries and regulators with authority over aspects of laboratory and institutional operations. But the design and implementation of controlling legislation, if done poorly, can often cause more damage than unmitigated laboratory risks themselves. Finding an appropriate balance between proper mitigation and the needs of science is precisely the challenge, one that international meetings bringing together scientists, biorisk professionals, and policymakers hope to help address.

What defines that proper balance will depend on the laboratory, the institution, and the country. Risk, risk perception, and risk tolerance naturally vary depending on the situation, and thus, the most efficient or effective way of reducing risk in one situation may be very different from the most efficient and effective way in another. The assessment and implementation of risk reduction strategies in laboratories has traditionally been beset with difficulties, with institutions and regulators not understanding where to begin or how to take a holistic and systematic approach to the process. As resources are often limited, it can be tempting for institutional management not to address risks at all, or issue blanket requirements that may not be appropriate for every situation, in an effort to avoid the costs of implementing what may seem to be an expensive risk management system. Although simple and seemingly "inexpensive," blanket proscriptions for reducing risk tend to generate gaps and create systemic inefficiencies, in both day-to-day operations as well as in risk reduction. Superficial measures will provide superficial protection. In the long run, unmitigated or improperly mitigated risks can cost laboratories, institutions, countries, and the international community dearly. The CWA 15793 Biorisk Management Standard is being increasingly recognized as an outline for a management system that can help reduce laboratory risks no matter the budget or situation. The only firm requirements are interest and time. Its flexibility, adaptability, and availability allow for rapid adoption by laboratory management and for the development of customized strategies for assessment, mitigation, and performance review. Its adoption by institutions brings peace of mind to national regulators, international collaborators, and the international community as a whole as to the efficient and systematic mitigation of safety and security risks in a laboratory.

The assembled group of international scientists and experts at the International Perspectives on Mitigating Laboratory Biorisks workshop agreed on biorisk management systems as a way forward in promoting biological safety and security in laboratories around the world. If the assembled delegates to the Biological Weapons Convention are in agreement, a statement from the 2010 Intersessional Meeting of States Parties in support of biorisk management could do much to increase the concept's exposure and legitimacy and provide momentum for future development and improvement. Arising from the community and confirmed by the esteemed delegates of the States Parties meeting, biorisk management could garner new strength to bridge divides between regulators and the regulated and 
could strengthen the concept of biosecurity in laboratories, institutions, and countries where it has heretofore had limited reach or effect.

Another consensus reached at the workshop was the important role of international cooperation by the scientific and expert communities to foster the evolution of the biorisk management field from its current state of development into the future. International discussions and input from multiple partners add legitimacy and relevance to future efforts, allow for a sharing of best practices, experience and resources leading to continual improvement, and allow existing international forums like the intersessional States Parties meetings to take up recent developments and galvanize national action in support for biorisk management.

As national governments strengthen local regulations on laboratory biorisks, international forums like the meetings of the Biological Weapons Convention should serve to underline the importance of harmonizing efforts between countries such that the mitigation of risks posed by dangerous pathogens and toxins does not necessarily entail an end to scientific cooperation for peaceful purposes. As mandated by Article $\mathrm{X}$ of the Convention, States Parties have a responsibility not to unduly hinder peaceful international cooperation in biology. International forums can serve to exchange ideas on how best to proceed with effective national mitigation strategies for different contexts while minimizing the need to erect barriers to cooperation. Efforts like the CWA 15793 Biorisk Management Standard facilitate international cooperation by promoting a common approach towards reducing risks that adds confidence to cooperating institutions. Utilizing risk management as a vehicle for increasing cooperation is a lofty goal that should be adopted by national governments and coordinated in international forums like the Meetings of the States Parties to the Biological Weapons Convention.

Finally, a common theme of the Workshop was education, training, and workforce competence. In efforts to consider next steps towards increasing international cooperation in the mitigation of laboratory biological risks, it will be important to address these concerns from the scientific and biorisk community and urge national governments in particular to support effective biorisk training programs. A properly trained workforce is essential for reducing laboratory risks, and international cooperation in training in combination with national and local training initiatives can help ensure workforces around the world are exposed to the latest best practices in mitigation, institutions understand the best methods to teach, and a common understanding of risks across countries provides a basis for future scientific and risk reduction cooperation. 


\section{Appendix A - Workshop Agenda}

\section{Day 1: 25 October 2010}

\section{Session 1: Laboratory Biorisk Management and the BWC}

08.00-08.30 Registration

08.30-08.45 Welcome and Opening Remarks

Prof. Dr. Hüseyin Avni Öktem, President of Turkish Biotechnology Association

08.45-09.05 Laboratory Biorisk Management and the Biological Weapons Convention Jen Bae, US Department of State

09.05-09.25 Case Study \#1 Challenges in Laboratory Biorisk Management Dr. Uwe Mueller-Doblies, Pirbright

09.25-09.45 Case Study \#2 Challenges in Laboratory Biorisk Management Dr. Ara Tahmassian, Boston University

09.45-10.05 Introduction to CWA 15793: Laboratory Biorisk Management Standard Dr. Gary Burns, AstraZeneca Pharmaceuticals

10.05-10.50 Group Photo and Break

10.55-11.15 Case Study \#4 Change Management/Imp Laboratory Biorisk Management Dr. Alberto Díaz Quiñonez, Mexico

11.15-12.45 Breakout Session: Challenges in Laboratory Biorisk Management Groups will be asked to address a set of specific questions and tasks across the breakout sessions. Discussions on strengths and weaknesses of status quo in managing lab biorisks and applicability of management systems, institutional roles and responsibilities.

12.45-14.15 Lunch

\section{Session 2: Risk Assessment and Mitigation}

14.15-14.35 Risk Assessment Tools and Applications

Dr. Mika Shigematsu, Japanese National Institute of Infectious Diseases

14.35-14.55 Engineered and Procedural Solutions for Laboratory Biorisk Management

14.55-15.15 Engineered and Procedural Solutions for Laboratory Biorisk Management Mr. Paul Langevin, Merrick \& Company 
15.15-15.30 Break

15.30-17.00 Breakout Session: Risk Assessment and Risk Mitigation Measures Groups will be asked to address a set of specific questions and tasks across the breakout sessions. Discussions on any requirements or constraints on conducting risk assessments, different risk assessment approaches, identify risk assessments needs/gaps; discussion on advantages and disadvantages of engineered vs. procedural, a Personnel Reliability Program (PRP) breakout group, and a waste disposal group.

\section{Day 2: 26 October 2010}

\section{Session 3: System Performance}

09.00-09.40 Rapporteur Reports from Day 1

Brief summaries of breakout sessions

09.50-10.10 Laboratory Audits and National Inspections

Dr. Se Thoe Su Yun, Singapore Ministry of Health

10.10-10.30 International Inspections: The Process Using CWA 15793

Dr. Paul Huntly, DNV Biorisk

10.30-11.00 Break

11.00-12.30 Breakout Session: Biorisk Management System Performance

Groups will be asked to address a set of specific questions and tasks across the breakout sessions. One to discuss strategies for promoting incident reporting/near misses, one on the role of inspections/audits, one on other performance measures for lab biorisk management.

12.30-14.00 Lunch

\section{Session 4: Training}

14.00-14.20 Case Study: What Biosafety Associations can Accomplish Dr. Larbi Baassi, Association Marocaine de Biosecurité

14.20-14.40 Case Study: What Biosafety Associations can Accomplish Dr. Edith Tria, Philippine Biosafety and Biosecurity Association

14.40-15.00 Promoting Sustainable Biosecurity Education and Dual Use Risks for Life Scientists Giulio Mancini, Centro Volta

15.00-15.30 Break 
15.30-17.00 Breakout Session

Groups will be asked to address a set of specific questions and tasks across the breakout sessions. One group - online training - what should it look like, what's currently available, what's needed. Other breakout topics - id other trainings, gap assessment, next steps/needs, training for lab workers vs biorisk professionals, role of biosafety associations. 4

\section{Day 3: 27 October 2010}

\section{Session 5: National Biorisk Oversight and Regulations}

09.00-09.30 Rapporteur Reports from Day 2

Brief summaries of breakout sessions

09.50-10.10 National Biorisk Regulations Case Study \#10

Dr. Won-Jong Jang, Konkuk University, Republic of South Korea

10.10-10.30 National Biorisk Regulations Case Study \#11

Dr. Sanders Banus, National Institute of Public Health and Environment, the Netherlands

10.30-10.50 National Biorisk Regulations Case Study \#12

Dr. Anwar Nasim, COMSTECH Secretariat Pakistan

10.50-11.20 Break

11.20-12.50 Breakout Session: National Biorisk Oversight and Regulations Groups will be asked to address a set of specific questions and tasks across the breakout sessions. What should be part of national oversight to meet international requirements, role of CWA 15793 and accreditation/certification, biosafety vs. biosecurity regulations, laboratory biorisk regulations as helping meet BWC and 1540 obligations?

\subsection{0-14.20 Lunch}

\section{Session 6: Closing Plenary}

14.20-14.50 Rapporteur Reports from Morning Day 3

Brief summaries of breakout sessions

14.50-16.00 Meeting Summary / Open Discussion

Discussion of lessons learned, biorisk challenges and solutions identified, and next steps / recommendations for the workshop report 


\section{Appendix B - Breakout Session Questions}

\section{Session 1: Laboratory Biorisk Management and the BWC}

- What challenges exist in managing biological risk in laboratories?

- What is a laboratory biorisk management system?

- How can such a system help overcome some of these challenges?

- What institutional roles and responsibilities are necessary for personnel to properly manage risk?

- What are some opportunities and obstacles that arise as a result of implementing a biorisk management system?

\section{Session 2 - Risk Assessment and Mitigation}

\section{2a. Risk Assessment}

- What is the purpose of a risk assessment?

- How is laboratory risk normally assessed in institutions in your country?

- Why can risk assessments be difficult to conduct?

- What are the advantages to conducting risk assessments in a robust, reproducible, and transparent manner?

2b. Risk Mitigation

- How should the assessment of risk be connected to strategies for improving safety and security in laboratories?

- What factors might be important for the successful implementation of risk mitigation strategies?

- How should decisions be made on the cost versus effectiveness of different mitigation measures?

- What are the advantages of relying on training and procedures as the primary and preferable mitigation strategy? What are the disadvantages?

- What are the advantages of relying on engineering solutions as the primary and preferable mitigation strategy? What are the disadvantages?

\section{Session 3: System Performance}

\section{3a. Incident Reporting}

- What constitutes a safety or security incident? When should an incident be reported?

- What details should be included in a report following a safety or security incident?

- How should institutional management review, assess, and act upon incident reports?

- What factors make an incident reporting system effective or ineffective?

- What are other ways of measuring how well risk management systems are performing?

\section{3b. Inspections and Audits}

- What sort of personnel should be charged with conducting inspections and audits in laboratories?

- What needs to be inspected and audited in a laboratory or institution, and in what manner? 
- How should institutional management review, assess, and act upon the results of inspections or audits?

- What are other ways of measuring how well risk management systems are performing?

\section{Session 4: Training}

\section{4a. Content in Training}

- Should biosafety and biosecurity issues be treated jointly or separately in training?

- Should training focus on practical skills or theoretical issues?

- What should be the role of management in deciding the content of training?

- How should the content of training change over time?

\section{4b. Methods of Training}

- Should training be conducted by outside experts, even international trainers, or should certain in-house personnel be responsible for training?

- What personnel in a laboratory should be trained, how often, and what factors could affect the audience and frequency of training?

- What role should computers and online technology have in training?

- How does one ensure a training program can be effectively maintained?

\section{Session 5: National Biorisk Oversight and Regulations}

\section{5a. Optional Considerations}

- What sorts of risk management policies should be developed by institutions rather than governments or international bodies?

- Should adherence and compliance to an international, performance-based standard like CWA 15793 be strictly voluntary on the part of individual institutions?

- What are the benefits and limits of using "best practices" to define a risk mitigation strategy?

- What role can voluntary biosafety and biosecurity associations play in laboratory biorisk management?

- Are there minimum requirements that government should mandate to allow a best practice environment to flourish? If yes, what are they?

\section{5b. Government Requirements}

- What responsibilities does the government have in the management of risk in laboratories?

- Should countries directly regulate work with particular agents as a way of mitigating biological risks?

- How would government oversight best operate to ensure laboratories and institutions are complying with regulations?

- Could performance-based risk management approaches effectively form a part of government regulation?

- What are the minimal requirements for effective biorisk management that fall exclusively under a government's jurisdiction? 


\section{Appendix C - Speaker Biographies}

\section{Larbi Baassi}

Dr Larbi Baassi is a Biologist-Chief Engineer in the National Institute of Hygiene (NIH) at the Ministry of Health of Morocco. In the NIH, Dr Baassi is in charge of the coordinating unit for the International Health Regulations (IHR) and since 2009, he has been also a coordinator of Biosafety implementation in Moroccan Public Health Laboratories. He holds a Ph.D in Immunology from Mohamed V University of Rabat, and has been working more than 17 years at NIH in Morocco. Dr Baassi is also Deputy Secretary General of the AMBS (Moroccan Association of Biological Safety).

\section{Sander Banus}

Dr. Sander Banus has been working at the National Institute of Public Health and the Environment (RIVM), of the Netherlands since 1998. After finishing his PhD in medical science on the topic of whooping cough he began work at the Advisory Service for the Inspectorate, Environment and Health division on the topics of CBRN and biosecurity. Sander is involved with the Environmental Incident Service as team leader of the national CBRN sampling team and as a biological incidents expert. Sander was project manager for the development of a mobile BSL-3 laboratory that can be fielded in case of a CBRN related incident. Since 2010 he is responsible for the installation of a Dutch biosecurity regime.

\section{Gary Burns}

After following an academic career in biochemistry and molecular biology for nearly 20 years, Gary began a career in health and safety working for the Health and Safety Executive, initially as one of HM Inspectors of Health and Safety and subsequently as a Specialist Inspector in the Genetic Modification section of HSE's Biological Agents Group. Gary was awarded his PhD in Biochemistry by the University of Manchester in 1975 and a Post-Graduate Diploma in Health and Safety by Aston University in 1994. In 1999 Gary joined AstraZeneca Pharmaceuticals in a biosafety advisory role and since 2006 has been employed as the company's Global Biosafety and Biosecurity Manager. Gary is a member of the UK Scientific Advisory Committee for Genetic Modification and a member and Past-President of the European Biosafety Association. He is also a member of the European Centre for Disease Prevention and Control Biorisk Expert Group. He served as Vice-Chair of CEN Workshop 31 which resulted in the publication of a CEN Workshop Agreement for a laboratory biorisk management standard (CWA 15793:2008). 


\section{José Alberto Diaz-Quiñonez}

Dr. Diaz-Quiñonez was born in the State of Sinaloa, Mexico and obtained his pharmaceutical-biologist license in chemistry from the Chemical-Biological Sciences Faculty of the Autonomous University of Sinaloa in 1994. Dr. Diaz-Quiñonez obtained a diploma on Technology Management at the Center for Applied Sciences and Technological Development from the National Autonomous University of Mexico (UNAM) and a biotechnology project management certificate from Technological Autonomous Institute of Mexico. He also received a doctoral degree in 2000 in Biomedical Sciences from the UNAM.

His earlier work focused on recombinant proteins and therapeutic antibodies, and established the Biotechnology Department at Laboratorios Silanes (Mexico) in 2003. Dr. Diaz-Quiñonez has completed technology transfer projects in the US (The Rockefeller University, SBH Sciences) and several Universities and research institutes in Mexico (2000-2007). Since 2007 his scientific research has focused on epidemiology and public health. He has occupied a variety of academic and administrative posts during his career. He is former Director of Diagnosis and Reference, National Institute of Epidemiologic Diagnosis and Reference (2007-2010). He has also been an associate professor at a number of educational institutions, including UNAM since 2001. Dr. Diaz-Quiñonez is professor of immunology at UNAM and has published articles in various journals in Mexico and internationally, as well as chapters in several books.

Dr. Diaz-Quiñonez is founder and currently president-elect, of the Mexican Biosafety Association (AMEXBIO), member of CEN Workshop 55 - Guidance on CWA 15793 (Laboratory biorisk management standard), and since 2004 he has served as technical advisor for WHO. Currently, Dr. Diaz-Quiñonez is the Head, Reference Laboratory - Laboratory Network of Epidemiological Surveillance and Research, Mexican Social Security Institute (Instituto Mexicano del Seguro Social) otherwise known as IMSS for the Mexico Ministry of Health.

\section{Paul Huntly}

Paul is a Principal Consultant with Det Norske Veritas (DNV), specializing in risk assessment associated with biological systems, in particular studies relating to laboratory biosafety and biosecurity (biorisk) measures. Paul has provided consultancy advice on biorisk and conducted biorisk audits and assessments for a variety of organizations. A microbiologist by training, Paul has specialized in the management systems approach to managing risk in scientific environments. Paul was also the Project Manager for the first internationally available standard for biorisk management system in the biological laboratories or known as the CWA 15793:2008 - Laboratory Biorisk Management Standard. He was closely involved in the concept and development of the Standard. Paul is currently Global Leader for the Biorisk group within DNV and, although based in Singapore, he works extensively throughout Asia and the rest of the world 


\section{Won-Jong Jang}

Won-Jong Jang, is a professor with the Department of Microbiology, College of Medicine at Konkuk University, Republic of South Korea. He has much interest in biosafety, and activated the Institutional Biosafety Committee (IBC) in KonKuk University. He has contributed to the establishment of a biosafety culture and organized training courses in his institution. He has acted as the chairman of the Executive Committee for the Biological Safety Level 3 (BSL3) facility and as the Senior Biosafety Officer in KonKuk University for over 3 years. In addition he has been devoted to the organization of the Korean Biological Safety Association (KOBSA) and acted as a board member.

\section{Paul Langevin}

Mr. Langevin has been involved with the planning, design, construction, commissioning and operations of containment laboratories (BSL2-3-4) for the last 27 years. Currently working for Merrick \& Company, Mr. Langevin is the Director of Laboratory Design Services and provides design and technical leadership on many high containment projects. Prior to Merrick, Mr. Langevin managed Biocontainment Design Services and was also the senior project manager for the Canadian Health Science Center for Human and Animal Health. He provides hands-on understanding of the operations of laboratories, having lead commissioning and laboratory decontaminations, biological testing of effluent and carcass disposal systems, and installation of containment systems. In addition to his duties at Merrick, Mr. Langevin currently provides training and consulting for biocontainment design and has served on international high containment projects.

\section{Giulio Mancini}

Giulio Mancini is Programme Officer at the Landau Network - Centro Volta (LNCV) of Como, Italy on nuclear and biological weapon proliferation prevention and disarmament, and biosafety/biosecurity enhancement tools and policies. He coordinates the LNCV programme on Global Biosecurity and the Biosecurity and Dual-Use Education projects. Giulio has also been involved in other projects in the LNCV "Science and Technology for Non Proliferation" Programme, including the work of the International Working Group on Transition Initiatives, studies on the "human dimension of non proliferation" and on the design of strategies for the "engagement of scientists with sensitive knowledge" in the framework of the G8 Global Partnership against the Spread of WMD and of the EU Instrument for Stability 2007-2011. Giulio has worked at LNCV since 2007. He holds a master's degree in International Relations and European Integration and a BA in Political Science, both from the Catholic University of Milan.

\section{Uwe Mueller-Doblies}

Dr. Uwe Mueller-Doblies is Head of Biosecurity at the Institute for Animal Health, Pirbright Laboratory, where he is responsible for biorisk management. He is responsible for biological containment, disinfectant testing, facility design, technical risk assessments, vector-borne viral diseases, and tick biology. He was Chairman of the International Veterinary Biosafety Workgroup. He earned his Pathology Part 2 in Virology and Immunology at the University of Cambridge in 1992 and his Degree in Veterinary Medicine at the Free University of Berlin in 1994. In 1999 he earned his Doctorate in Veterinary Medicine, concentrating in veterinary virology, at the University of Zurich. He was also a Diplomate of the European College of Veterinary Public Health in Population Medicine in 2005. 


\section{Anwar Nasim}

Dr. Anwar Nasim, a molecular geneticist- the science which involves studying mechanisms which control heredity, is a world renowned Geneticist. He obtained his Ph.D. from University of Edinburgh. He spent twenty-three years in Canada affiliated with federal research organizations. He also did some research work at Max Planck Institute, Tubingen, Germany, and the Biology Department of Stanford University, California USA. He spent four years doing research in King Faisal Specialist Hospital in Riyadh in the early nineties. On return to Pakistan, he is presently Advisor Science in COMSTECH, OIC Standing Committee on Scientific and Technological Cooperation and is chairman of the National Commission on Biotechnology. He feels that scientific research must lead to economic development and society must benefit from it.

He has been awarded Pride of Performance and Sitara-e-Imtiaz by Government of Pakistan for his outstanding contributions as a geneticist. He is a fellow of TWAS, Islamic World Academy of Sciences, and fellow of Pakistan Academy of Science. He received Overseas Pakistani's Institute (OPI) award for his outstanding services for promotion of science in Pakistan.

\section{Huseyin Avni Oktem}

Prof. Huseyin Avni Öktem recieved his BSc in Biological Sciences and MSc in Biochemistry from Middle East Technical University in Ankara, Turkey, followed by a certificate in Neurochemistry and a PhD in Biochemistry from Josef Attila University in Hungary in 1990. He worked for a year at the Plant Biotechnology Institute at Texas Tech University. He established one of the first plant genetic transformation research facilities in Turkey. At the age of 36, he became a full professor of Biochemistry at METU. He was involved in more than 100 academic and industrial R\&D projects as Project director or researcher. He has more than 125 scientific publications in international and national journals, six utility model-patents, and one pending patent applications. He is the co-founder and executive board member of the METU-Nanotechnology-Nanobiotechnology Research Center. He has acted as a referee and consultant for various governmental and private organizations. He is the chairman of Turkish Biotechnology Association, which is the official representative of the European Federation of Biotechnology in Turkey.

Prof. Öktem is co-founder and owner of two companies: OBiTEK-Middle East United Technologies Ltd. Co. and NANObiz NanoBioTechnological Systems R\&D and Consultancy Ltd. Co. He located both companies in METU Technopolis. OBiTEK won TUSIAD/TTGV/TÜBITAK Nanobiotechnology Technology Awards 2007 which is the leading technology contest of Turkey. He is leading a research team of 20 people. He currently holds a full professor position at the Middle East Technical University and provides technology coaching services to more than 60 companies, some of which are the leaders in their sector in Turkey. He is responsible from strategic planning and R\&D operations at NANObiz. 


\section{Mika Shigematsu}

Mika Shigematsu graduated from Kochi University in Japan and has been registered on the Japanese national board as a physician since 1990. Her major area of clinical medicine is general internal medicine, infectious diseases and life-style associated diseases. Dr. Shigematsu received her PhD in Internal Medicine and Microbiology from Kyushu University Graduate School, and a Diploma and MSc in Infection Control from the London School of Tropical Medicine of the University of London. She joined the National Institute of Infectious Diseases (NIID) of Japan in March 2002 after a two and a half year post-doctoral attachment at the Health Protection Agency in London. She currently holds the position of Senior Research Scientist in Infectious Disease Surveillance Center at NIID. Her expertise covers a wide range of preventative medicine and practice, which includes bacteriology, infection control, public health capacity building, communicable disease epidemiology and surveillance, molecular epidemiology, quantitative risk assessment of food-borne outbreaks, laboratory biosafety and biosecurity management and training, and risk communication training for public health personnel. She has worked closely with the Division of Biosafety Control and Research of NIID and the International Biological Threat Reduction Program at Sandia National Laboratories in recent years on biosecurity risk assessment and management, as well as biosafety. She is a qualified Infection Control Doctor (1999, Japan) and holds an IATA Diploma on Dangerous Goods Regulation (since 2007). She is a full member of A-PBA, serving as a committee member from 2007 to 2008.

\section{Ara Tahmassian}

Ara Tahmassian is the Associate Vice President for Research Compliance at the Boston University and Boston Medical Center. As the Institutional Official, he is responsible for the development and implementation of institutional programs and operational strategies for all non-financial regulatory compliance issues. Programs reporting to him directly include: Environmental Health and Safety; oversight of the development and implementation of all safety and emergency response plans for the National Emerging Infectious Disease Laboratory (NEIDL), which is one of the two National Biocontainment Laboratories currently under construction at BU; Institutional Biosafety, Radiation Safety and Laboratory Safety Committees; Animal Care and Use Programs; Financial Conflict of Interest; Responsible Conduct of Research and Offices of Sponsored Research Programs. He is also the Research Integrity Officer and is the Principal Investigator for the core BSL-3 select agent laboratory at BU. He retired from University of California, San Francisco in 2006 as the Associate Vice Chancellor for Research where he had a similar portfolio. Dr. Tahmassian has a B.Sc. in Nuclear Engineering and a Ph.D. in Health Physics, is a Diplomate of the American Board of Sciences in Nuclear Medicine, and serves on a number of national and international panels. 


\section{Edith Tria}

Dr. Edith Sangalang Tria is the founding President of the Philippine Biosafety and Biosecurity Association Inc (PhBBA), which has its origins from the Philippines Department of Health Technical Working Group (TWG). She is currently the Chairperson of the Technical Working Group to develop a Manual of Standards for the National Laboratory Biosafety and Biosecurity Program (NLBBP). As a Clinical Pathologist, she had served for 10 years as a Regulatory Officer and Quality Assurance Program Consultant of the Bureau of Research and Laboratories (BRL), Philippines Dept of Health Licensing Section. She has completed her Masteral Course in Management, Major in Public Administration, and has completed the full academic requirements for Masteral Studies in Molecular Biology and Biotechnology at the Philippine State University. She has served as Head of Microbiology and Molecular Biology Section of the Bureau of Research Laboratories, Philippines Dept of Health. Currently, she is the Department Head of the Philippine Infectious Disease Medical Center, San Lazaro Hospital Central Laboratories, which houses the only BSL3 lab facility in the country, is working to institutionalize the NLBBP in her institution, and is engaged in organizing the conduct of its advocacy symposia nationwide. Simultaneously, she assisted in the organization of PhBBA local chapters in the Mindanao region.

As a member of ABSA and APBA, and EXCO Member of APBA, she was able to promote the PhBBA to become a member of the International Federation of Biosafety Associations. She has been instrumental in linking various multisectoral stakeholders from the Defense, Agriculture, Academic, Health, Science and Technologies sectors and Local Government Units in building partnership related to biosafety and biosecurity concerns in the country.

\section{Se Thoe Su Yun}

Se Thoe Su Yun, PhD, is the Head of the Biosafety Legislation Branch of the Singapore Ministry of Health. The Biosafety Legislation Branch is responsible for the administration and enforcement of the Biological Agents and Toxins Act, which is intended to safeguard national biosafety and biosecurity. As such, Se Thoe and her colleagues are responsible for the development of biosafety and biosecurity policy, the establishment and enforcement of the framework to support the policy. Certification and inspection of high containment laboratories is one of the many responsibilities of the Branch.

Prior to her employment with the government, Se Thoe worked as a Research Scientist and Scientific Officer with the Singapore General Hospital. She set up the Molecular Laboratory in the Department of Pathology of the hospital, and was primarily responsible for the development of molecular testing, quality, and safety control of the Molecular and the National HIV Reference Lab. She was also actively involved in and contributed towards the development of the biosafety policy for the BSL-3 Lab in the Department. 


\section{Appendix D - Participants}

\begin{tabular}{|c|c|c|}
\hline Last Name & First Name & Country \\
\hline Abdulrahaman & Furrarah & Libya \\
\hline AL Eryani & Yaser Mohammed & Yemen \\
\hline Alami & Redi Gul & Afghanistan \\
\hline Alshaibani & Khaled Saeed & Yemen \\
\hline Arzumanyan & Nune & Armenia \\
\hline Baassi & Larbi & Morocco \\
\hline Bae & Jennifer & United States \\
\hline Banus & Sander & Netherlands \\
\hline Burns & Gary & United Kingdom \\
\hline Copping & Steven & United Kingdom \\
\hline Oliveira de Souza & Lucia & Switzerland/Brazil \\
\hline Diaz-Quinonez & Jose Alberto & Mexico \\
\hline Dizon & Florencio Concengco & Philippines \\
\hline Heisz & Marianne & Canada \\
\hline Hoang & Ha Thi Thu & Vietnam \\
\hline Huntly & Paul & Singapore \\
\hline Jang & Won-Jong & Republic of Korea \\
\hline Joyan & Ahmad Waleed & Afghanistan \\
\hline Karapetyan & Sergey & Armenia \\
\hline Kervers & Onno & Netherlands \\
\hline Langevin & Paul & Canada \\
\hline Lepeshkin & Gennadiy & Russia \\
\hline Magay & Alena & Kazakhstan \\
\hline Mamadaliyev & Seidigapbar & Kazakhstan \\
\hline Mertsching & Juergen & Germany \\
\hline Miadzvetski & Siarhei & Kazakhstan \\
\hline Müller-Doblies & Uwe & United Kingdom \\
\hline Nasim & Anwar & Pakistan \\
\hline Oktem & Huseyin Avni & Turkey \\
\hline Radwan & Moustafa Ismail & Egypt \\
\hline Sevilla-Reyes & Edgar & Mexico \\
\hline Smith & Jacqueline & United States \\
\hline Soliman & Mohamed & Egypt \\
\hline Tahmassian & Ara & United States \\
\hline Trataris & Anastasia & South Africa \\
\hline Tria & Edith & Philippines \\
\hline Mancini & Giulio & Italy \\
\hline Se Thoe & SuYun & Singapore \\
\hline Yunus & Zalini & Malaysia \\
\hline Shigematsu & Mika & Japan \\
\hline
\end{tabular}




\title{
Distribution
}

\author{
UNLIMITED RELEASE
}

sanddocs@sandia.gov, Sandia Technical Library (electronic copy) 
Sandia National Laboratories 